PNL-4779

\title{
1982 Annual Report: Biomass Thermochemical Conversion Program
}

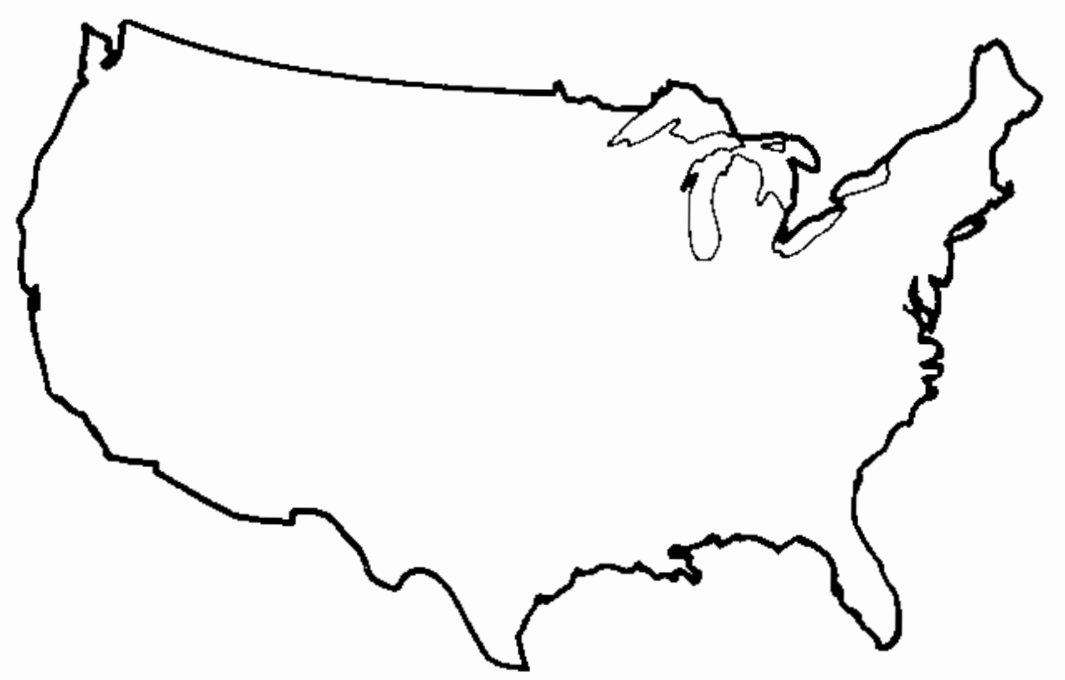

January 1983

G.F. Schiefelbein

D.J.Stevens

M.A. Gerber

Biomass Program Office

Pacific Northwest Laboratory

Operated for the U.S. Department of Energy

by Battelle Memorial Institute 


\title{
DISCLAIMER
}

This report was prepared an an account of work sponsored by an agency of the lnited States Government. veither the Lited States Covernment nor any agency thereot, nor any of their emplovees. rakes any waranty, express or implied, or assumes any lexal liability or respo usibility for the accuracy, completeness. or usefulness of any information, apparatus, product, or procesi disc lested, or represents that its use would not intsinge privalely owned rights.

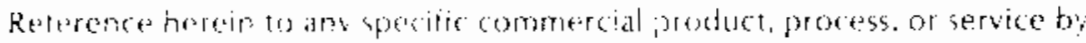
trade nambe. Tiademark. manutacturer. or otherwise. does not necessarily constitute or imply its endersement, recomrendation, or favoring by the l.mited States Covernment or anvagence therout. The views and opinions of

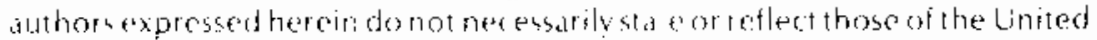

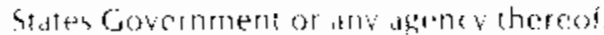

\author{
PACIFIC NORTHWLST LABORATORY \\ (y)terded by \\ BATIJLLE \\ tor the \\ U VITED STATES DFPARTMENT OI FERGY \\ under Combract of-ACO)6-76RIO 1830
}

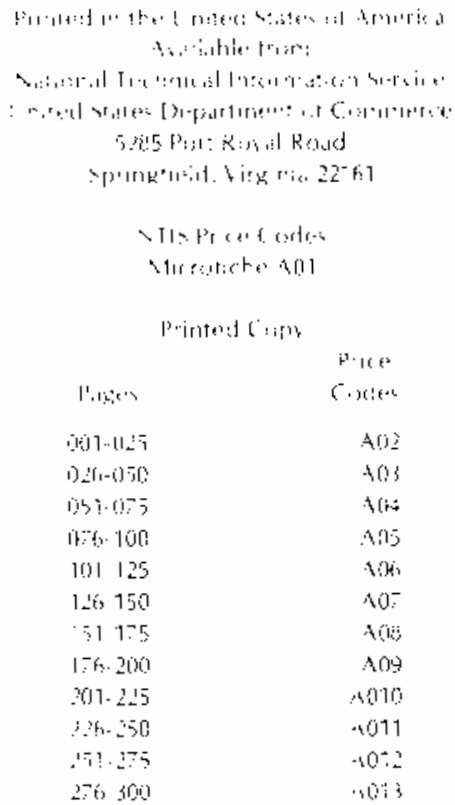


1982 ANNUAL REPORT:

BIOMASS THERMOCHEMICAL

CONVERSION PROGRAM

G. F. Schiefelbein

D. J. Stevens

M. A. Gerber

Biomass Program 0ffice

January 1983

Prepared for

the U.S. Department of Energy

under Contract DE-AC06-76RL0 1830

Pacific Northwest Laboratory

Richland, Washington 99352 
TABLE OF CONTENTS

EXECUTIVE SUMMARY . . . . . . . . . . . . . . . . . . . 1

Program Objectives and Strategy .............. i

Program Organization .................. . . . . i

Gasification Technology . . . . . . . . . . . . . i i

Pyrolysis Technology................. . . . iv

Direct Liquefaction Technology ............. . v

Direct Combustion Technology .............. vi

Program Support Activities... . . . . . . . . . . . vi

Outstanding Accomplishments in 1982 . . . . . . . . . vi

INTRODUCTION . . . . . . . . . . . . . . . . . . . . 1

PROGRAM OBJECTIVES AND STRATEGY .................... 5

GASIFICATION TECHNOLOGY . . . . . . . . . . . . . . . 8

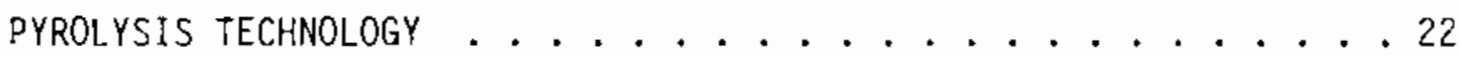

DIRECT LIQUEFACTION TECHNOLOGY . . . . . . . . . . . . . . 33

DIRECT COMBUSTION TECHNOLOGY . . . . . . . . . . . . . . . 46

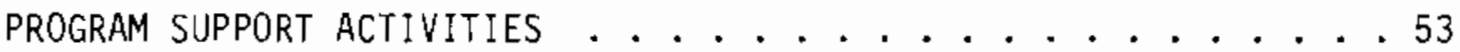

APPENDIX A - BIBLIOGRAPHY . . . . . . . . . . . . . 56

DISTRIBUTION . . . . . . . . . . . . . . . . . . . . . . . . . 


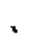

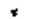

.

. 


\section{EXECUTIVE SUMMARY}

Bionass represents an important but under utilized energy resource in the United States. The Congressional Office of Technology Assessment has estimated that with proper resource management and the development of efficient conversion processes, the potential contribution of biomass to U.S. energy demand could range as high as 17 quadrillion Btu per year; a lnost $20 \%$ of current U.S. energy consumption.

The Thermochemical Conversion Program is part of DOE's Biomass Energy Technology Division, Office of Renewable Energy. Pacific Northwest Laboratory has been designated the lead laboratory for the Biomass Thermochemical Conversion Program with responsibility for overall field management of the program. This report provides a brief overview of the Thermochemical Conversion Program's activities and major accomplishments during fiscal year 1982 .

\section{Program 0bjectives and Strategy}

The objective of the Biomass Thermochemical Conversion Program is to generate scientific data and fundamental biomass conversion process information that, in the long term, could lead to establishment of cost effective processes for conversion of biomass resources into clean fuels and petrochemical substitutes. The goal of the program is to improve the data base for biomass conversion by investigating the fundamental aspects of conversion technologies and exploring those parameters which are critical to these conversion processes. 
To achieve this objective and goal, the Thermochemical Conversion Program is sponsoring high-risk, 1ong-term research with high payoff potential which industry is not currently sponsoring, nor is likely to support.

Thermochemical conversion processes employ elevated temperatures to convert biomass materials into energy. Prozess examples include:

- Combustion to produce heat, steam, electricity, direct mechanical power;

- Gasification to produce fuel gas or synthesis gases for the production of methanol and hydrociarbon fuels;

- Direct liquefaction to produce heavy oils or distillates;

- Pyrolysis to produce a mixture of oils, fuel gases, and char.

Biomass feedstocks have unique properties when compared to other solid fuels, such as coal, which offer great potential advantages for biomass thermochemical conversion processes. Biomass is highly reactive which means these feedstocks can be decomposed and converted at much lower temperatures than coals, making these processes more efficient and less costly. Biomass feedstocks also have much lower ash and sulfur content than coais. The lower sulfur conterit greatly reduces gas cleanup costs and allows biomass to be reacted directly with catalysts without catalyst poisoning problems. The research activities sponsored by the Biomass Thermochemical Conversion Prcgram are directed toward exploiting these natural advantages of biumass.

\section{Program Organization}

The research activities sponsored by the Thermochemical Conversion Program can be divided into the following five areas: 
1. Gasification Technology

2. Pyrolysis Technology

3. Direct Liquefaction Technology

4. Direct Combustion Technology

5. Program Support Activities

The remainder of this paper briefly describes Program activities and major accomplishments in each of these areas for fiscal year 1982.

\section{Gasification Technology}

Gasification of biomass can be achieved by reacting biomass with steam, at moderately high temperatures, to produce a combustible gas mixture containing large quantities of hydrogen and carbon monoxide. Heat is provided to the gasification reactor by either combusting a portion of the biomass with air or oxygen, or by indirectly heating the reactor. When air is used to heat the gasifier, the nitrogen in the air significantly dilutes the product gas, and a low Btu gas with a heating value of 90 to $200 \mathrm{Btu} / \mathrm{SCF}$ is produced. Low Btu fuel gas is limited by the restrictions that the gas must be used at or near the site of production in a ciose coupled process. The high nitrogen content of low 8tu gas precludes its use for synthesis of liquid fuels.

If nitrogen is eliminated from the product gas a medium Btu gas with a heating value ranging from 300 to 600 Btu can be produced. Medium Btu gas is suitable for substitution for fuel ojl and natural gas in most applications and for the synthesis of liquid fuels. 
The gasification research activities sponsored by the Biomass Thermochemical Coriversion Program are directed toward exploiting the unique properties of biomass. Specific research projects include:

- Research on indirect reactor heat'ng methods at the University of Missouri-kolla, Texas Tech University and Battelle-Coiumbus Laboratories,

- Research on high pressure (up to 500 psia) steam-oxygen gasification of biomass in a fluidized bed reactor at the Institute of Gas Technology, arid

- Research on producing synthesis gas via catalytic gasification at Pacific Northwest Laboratory and via oxygen gasification at Texas Tech University.

\section{Pyrolys is Technology}

Pyrolysis refers to the thernal decompcisition of biomass in an oxygen-free environment. Conventional pyrolysis produces products consisting of about one third each gases, pyrolysis oil, and char. Recently, researchers have discovered that the yields of higher valued light liquid hydrocarbons and gases can be increased to as high as $95 \%$ if biomass is heated very rapidly. These high valued products contain up to $20 \%$ ethylene and BTX (benzene, toluene, and xylene) useful as fuels, octane enhancers, and petrochemical feedstocks.

During 1982, the Thermochemical Conversion Program sponsored research projects in the area of biomass pyrolysis including;

- Determination of individual sequential pyrolysis mechanisms at the Solar Energy Research Institute (SERI),

- Determination of the effects of pressure on biomass pyrolysis at the University of Hawaii,

- Research at the Solar Energy Research Institute on a unique entrained, ablative fast pyrolysis reactor for supplying the high heat fluxes required for fast; pyrolysis, 
- Work on rapid pyrolysis of biomass in atmospheres of hydrogen and methane to increase the yields of olefin and BTX products at Brookhaven National Laboratory,

- Research at the Georgia Institute of Technology on an entrained rapid pyrolys is reactor, and

- Determination of the technical feasibility of burning biomass derived pyrolytic oils in a direct fired gas turbine at Teledyne CAE.

\section{Direct Liquefaction Technology}

The Biomass Thermochemical Conversion Program is sponsoring research on the direct liquefaction of biomass. In this research, biomass slurries are heated to moderate temperatures at high pressures with a catalyst in a reducing atmosphere of carbon monoxide and hydrogen. The goal of this research is to produce liquid products which could be used as substitutes fuel oils, and distillate fractions which could potentially be used for diesel fuels, octane enhancers, and other related uses.

During 1982, D0E sponsored research in direct iiquefaction has focused on evaluating the technical feasibility of existing process concepts and conducting research on new concepts which could lead to major technical advances. Specific projects included:

- Completion of final report on the multi-year operation of the Albany, Oregon Direct Liquefaction Facility by Wheelabrator Clean Fuels Corporation,

- Research on an aqueous phase liquefaction process at Lawrence Berkeley Laboratory,

- Extensive characterization of biomass derived oils produced in the Albany, Oregon Direct Liquefaction Facility by Pacific Northwest Laboratory,

- Research on advanced high pressure slurry feeding systems and liquefaction reactor design at the University of Arizona, and

- Studies of potential new direct liquefaction catalysts at SRI International and Lawrence Berkeley Laboratory. 


\section{Direct Combustion Technology}

Direct combustion of biomass feedstocks, particularly wood, is a)ready widely practiced by the private sector. Direct combustion projects funded by the Biomass Thermochemical Conversion Progran have focused on unique, innovative combustion systems. These include:

- Research on a directly fired wood combustor/gas turbine system at Aerospace Research Corporation, and

- Adaption of Stirling engire external combustion systems to biomass fuels at United Stirling, Incorporated. Figure 22 depicts the Stirling engine combustion chamber heat exchanger.

\section{Program Support Activities}

During 1982, the Thermochemical Conversion Program sponsored additional research activities with the goal of supporting major program elements. These activities included:

- Initiation of a wood supply infrastructure of sites capable of supplying wood to intermediate size (500-200 tons/day) biomass conversion facilities by Pyros, I'ncorporated,

- Completion of a "Solar Cost Data Bank" study by SRI International on biomass feedstock/conversion technology options,

- Compilation of a catalog of Bionass Thermochemical Conversion projects by EnergyTrack, Incorporiated, and

- Completion of a technoeconomic study by Science Applications, Incorporated to assess the applicability of advanced biomass gasification concepts to the production of methanol.

\section{Outstanding Accomplishments in 1982}

Outstanding accomplishments of the Bionass Thermochemical Conversion Program during this fiscal year ..982 include: 
- Achieved greatly increased carbon conversions and reactor throughput rates in an indirectly heated research gasifier at Battelle-Columbus Laboratories. The $\mathrm{BCL}$ entrained gasifier utilizes a recirculating sand system to provide heat to the gasification reactor. The hot sand is heated in an entrained bed combustor by burning biomass or char and fed to the gasifier to serve as a hot fluidizing medium. Reactor internals which create highly turbulent mixing zones were installed in the reactor in 1982. Carbon conversions in the modified reactor increased from 60 to $90 \%$ at reactor throughputs as high as $1860 \mathrm{lb} / \mathrm{hr}-\mathrm{sq} \mathrm{ft}$, which is about six times greater than that achieved in conventional fluidized bed reactors.

- Showed that catajytic gasification of biomass was feasible at elevated pressures. The catalytic fluidized bed gasifier at Pacific Northwest Laboratory was modified and successfully operated at pressures up to 150 psia to determine the effects of pressure on catalyst performance. This fluidized bed research gasifier utilizes a $\mathrm{Ni}-\mathrm{Co}-\mathrm{Mo} / \mathrm{SiO}_{2}-\mathrm{Al}_{2} \mathrm{O}_{3}$ catalyst as a fluidizing mediun to produce a synthesis gas contairing the correct molecular ratio of hydrogen and carbon monoxide for methanol production directly within the reactor. Preliminary analysis of data obtained shows that catalytic gasification at elevated pressures is technically feasible. Further analys is will be performed to determine the effect of pressurized operation on process economics. The Pacific Northwest Laboratory catalytic gasification research unit is shown in Figure 9.

- Achieved increased efficiency in the entrained flow, ablative fast pyrolysis reactor at the Solar Energy Research Institute. SERI is conducting research to determine the feasibility cf using this concept to supply the high heat fluxes needed for rapid pyrolysis. The unique reactor is capable of providing heatup as high as $500,000^{\circ} \mathrm{C} /$ second at the surface of a biomass particle, Ouring 1982, SERI increased operating efficiencies by modifying the reactor to eliminate feedstock channeling. SERI also showed that low steam/biomass ratios could be used, lowering process steam requirements. The reactor is shown in Figure 13.

- Determined that the combustion gases from a pressurized wood combustor can be used to directiy power a gas turbine after cleanup in a series of cyclories. Aerospace Research Corporation accumulated 200 hours of test operation of a $375 \mathrm{KW}$ wood fired combustor/gas turbine systern without evidence of corrosion or erosion of turbine components. Data obtained on the combustion gases entering the turbine indicated that 80 to 90 percent of the particles present were less than $0.5 \mathrm{~m}$ in diameter, which strongly suggests that turbine erosion will not be a problem. The Aerospace Research combustor/gas turbine unit is shown in Figure 23. 


\section{-}




\section{INTRODUCTION}

Biomass represents an important but under utilized energy resource in the United States. Wood and forest product residues, grasses, agricuitural crops and their residues, animal wastes and other biomass resources currently supply nearly three percent of total U.S. energy consumption. As an abundant, renewable, domestic energy resource, biomass can help the Unjted States reduce its dependence on imported oil and natural gas.

The Congressional Office of Technology Assessment (OTA) has estimated that with proper resource management and the development of efficient conversion processes, the potential contribution of biomass to U.S. energy demand could range as high as 17 quadrillion Btu per year; almost $20 \%$ of current U.S. energy consumption. (1) The Office of Technology Assessment has also indicated that biomass resources and conversion processes, if managed properly, are potentially more environmentally acceptable than many other synfuels. If this valuable resource is to be fully utilized for reducing U.S. dependence on imported $0 i 1$, additional research is needed on converting biomass into more useful energy forms.

Thermochemical conversion processes offer great potential for effectively utilizing biomass resources in terms of both gross energy use and displacement of conventional petroleum fuels.

(1) Energy from Biological Processes, Volumes I and II, Office of Technology Assessment, Congress of the United States, washington, D.C. 20510. 
Thermochemical conversion processes employ elevated temperatures to convert biomass materials into energy. Process examples include:

- Combustion to produce heat, steam, electricity, direct mechanical power and combinations of these;

- Gasification to produce low or medium Btu fuel gas;

- Gasification to produce synthesis gas for the production of methanol or mixed alcohol fuels, Fischer-Tropsch hydrocarbon liquids and gasoline, ammonia, or synthetic natural gas (SNG);

- Direct liquefaction to produce heivy oils or, with upgrading, lighter boiling liquid products such as distillates, light fuel oils, gasoline and chemicals;

- Pyrolysis to produce a mixture of pyrolytic oils, fuel gases, char and chemical feedstocks.

Biomass feedstocks have unique properties when compared to other solid fuels, such as coal, which greatly enhance the advantages of biomass thermochemical conversion processes. Biomass feedstocks have a very high content of volatile matter; typically $70-90 \%$ on a dry weight basis versus $30-40 \%$ for typical coais. The high volatile matter content allows biomass feedstocks to be decomposed very rapidly and at relatively low temperatures. Biomass chars are much more reactive than coal chars. The high reactivity of biomass means these feedstocks can be decomposed and gasified at much lower temperatures than coals, making these processes more efficient and less costly. Biomass feedstocks generally have much lower ash contents than coal, greatly reducing handling and ash disposal problems. In addition, the low sulfur content of biomass feedstocks greatly reduces gas cleanup costs and allows biomass to react directly in the presence of catalysts without catalyst poisoning problems. Therefore, it is clear that dramatic improvements in biomass thermochemical conversion processes are possible by addressing and exploiting the unique features of biomass. (1) 
The U.S. Departinent of Energy is actively encouraging increased utilization of biomass resources through research projects sponsored by the Biomass Thermochemical Conversion Program. This research is directed toward exploiting the natural advantages of biomass. The Thermochemical Conversion Program is part of DOE's Biomass Energy Technology Division, Office of Renewable Energy. Pacific Northwest Laboratory* has been designated the Lead Laboratory for the Biomass Thermochemical Conversion Program with responsibility for overall field management of the Program. The organization of this program is shown in Figure 1. This report provides a surmary of the Thermochemical Corversion Program research activities during fiscal year 1982.

* Pacific Northwest Laboratory is operated for the U.S. Department of Energy by Battelle Memorial Iristitute under Contract DE-AC06-76 RL0 1830 . 


\section{PROGRAM ORGANIZATION}

\begin{tabular}{|c|}
\hline DEPARTMENT OF ENERGY \\
SECRETARY \\
\hline DEPUTY SECRETARY \\
\hline UNDER SECRETARY \\
\hline ASSISTANT SECRETARY \\
CONSERVATION AND RENEWABLE \\
ENERGY \\
\hline DEPUTY ASSISTANT SECRETARY \\
RENEWABLE ENERGY \\
\hline \\
\hline OFFICE OF RENEWABLE TECHNOLOGY \\
\hline PEAD LABORATORY \\
\hline PIOMASS ENERGY TECHNOLOGY \\
DIVISION \\
\hline
\end{tabular}

Figure 1. Organization of the Biomass Thermochemical Conversion Program 


\section{PROGRAM OBJECTIVES AND STRATEGY}

The objective of the Biomass Thermochemical Conversion Program is to generate scientific data and fundamental biomass conversion process information that, in the long term, could lead to establishment of cost effective processes for conversion of biomass resources into clean fueis and petrochemical substitutes. Areas of research inciuded in the program are pyrolysis, gasification, direct liquefaction and combustion of biomass. The goal of the progran is to improve the data base for biomass conversion by investigating the fundamental aspects of conversion technologies and exploring those parameters which are critical to these conversion processes.

To achieve this objective and goal, the Thermochemical Conversion Program is sponsoring high-risk, long-term research with high payoff potential which industry is not currently sponsoring, nor is likely to support. Innovative basic research concepts are initially selected on the basis of program research needs, the concepts' potential contribution to advancing the state-of-the-art of biomass conversion and the availability of research funds.

Initial research usually consists of scientific verification of the technical feasibility (proof of principle) of the individual research concept. Concepts passing the preliminary technical feasibility test are frequently studied further in continuous process research units. These smal1-scale research units allow the concept to be further investigated under realistic conditions in a continuous, dynamic, interactive node. This stage of research allows the evaluation of variations in operating parameters in a continuous process environment 
and the determination of material and energy balances which are critical to determining the potential of the process. Individual concepts are then combined into an integrated process. The integrated process is evaluated to estimate process economics at comercial scale. Integrated processes exhibiting favorabie economic projections are then made available for transfer to the private sector.

To ensure the maximum opportunity for technology transfer to the private sector, industrial interest and involvement is sought at all stages of research. However, industrial interest and involvement is expressed most strongly in determining scale-up factors and commercial economics after the technical feasibility of a concept has been fully evaluated in continuous research units. The evolution and transfer of basic research concepts into integrated processes useful to industry is shown in Figure 2 .

The research activities sponsored by the Thermochemical Conversion Program can be divided intu the following f"ve areas:

1. Gasification Technology

2. Pyrolysis Technology

3. Direct Liquefaction Technology

4. Direct Combustion Technology

5. Program Support Activities

Research in each of these program areas for fiscal year 1982 is discussed in the following sections of this report. 


\section{PROGRAM APPROACH}

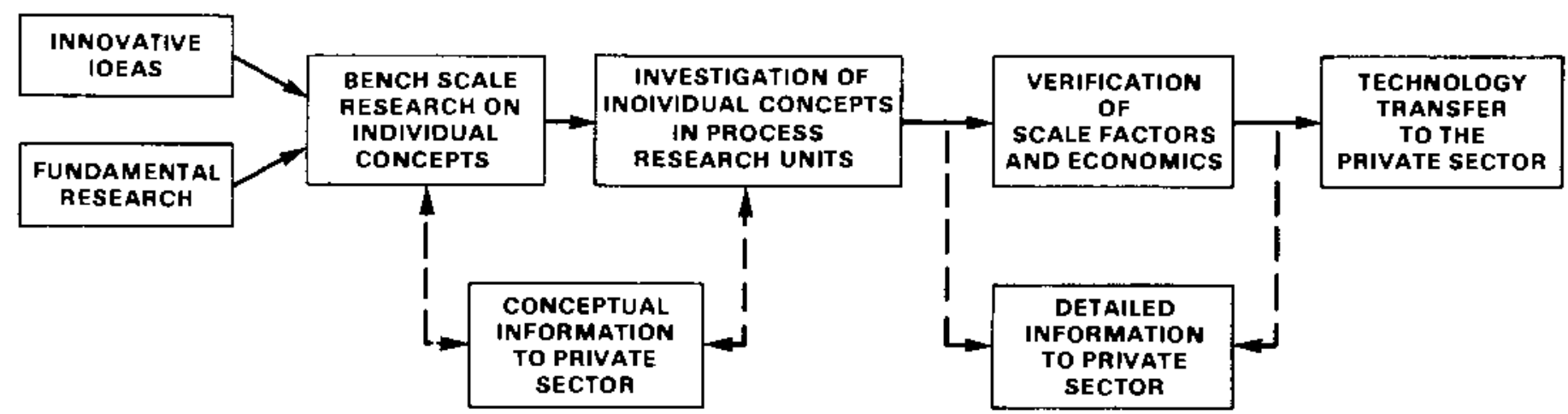

Figure 2. Evolution and Transfer of Basic Thermochemical Conversion Research to the Private Sector 


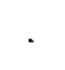




\section{GASIFICATION TECHNOLOGY}

Gasification of biomass can be achieved by reacting biomass with steam, at moderately high temperatures, to produce a combustible gas containing large quantities of hydrogen and carbon monoxide. As shown in Figure 3, heat is provided to the reactor by either combusting a portion of the biomass with air or oxygen, or by indirectly heating the reactor.

If air is used to heat the gasifier, the nitrogen in the air significantiy dilutes the product gas, and a low Btu gas is produced. Low Btu gas typically has a heating value ranging from 90 to 200 Btu/SCF. Today, low Btu gasification of biomass is considered to be a commercial technology. Low Btu gas can substitute for natural gas and oil to fire boilers, subject to the following limitations:

- Low Btu gasifjers must be close coupled to boilers to take advantage of the high temperature of the gas leaving the gasifier.

- Burning low Btu gas in a boiler will frequently result in boiler derating unless expensive modifications are made to the boiler.

Low Btu gas can also be used to fuel internal combustion engines in place of gasoline and diesel fuel provided that the gas is sufficiently cleaned and cooled. However the efficiericy of the engine will be reduced by about 20 percent.

If nitrogen is eliminated from the product gas of a biomass gasifier by heating it indirectly or with oxygen, a medium Btu gas can be produced. Medium Btu gas has a heating value typically ranging from 300 to $600 \mathrm{Btu} / \mathrm{SCF}$, and is much more versatile than low Btu gas. 


\section{PRINCIPLES OF GASIFICATION}

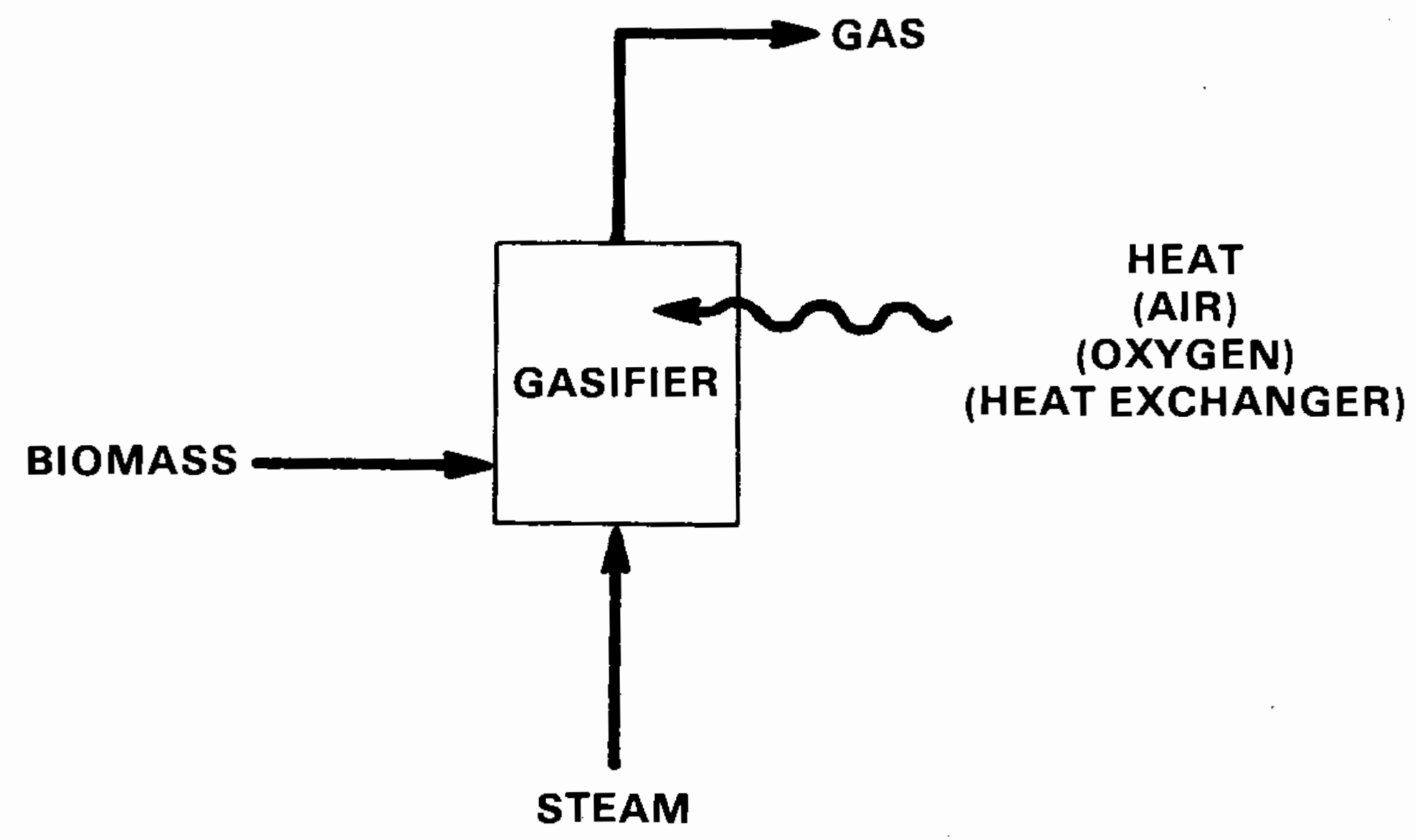


Because of its higher heating value, it possesses the following advantages over Low Btu gas:

- Medium Btu gas can be used in nearly all boiler retrofit applications without any boiler derating problems.

- Medium Btu gas produces a higher flame temperature than low Btu gas making it suitable for retrofitting critical processes such as lime recovery kilns in the pulp and paper industry which currently use fuel $0 i 1$ or natural gas. These applications require high flame temperatures but limited volumetric flow rates of combustion gases.

- Medium Btu gas has two to five times the energy density of low Btu gas allowing it to be transported moderate distances by pipeline at a reasonable cost.

- Since there is no nitroger diluting the gas, medium Btu gas can be used for the synthesis of derived liquid fuels.

Medium Btu fuel gas can also be produced from coal. The major disadvantage of coal gasification is that coal is not very reactive. Large quantities of oxygen are required to achieve sufficiently high reactor temperatures and reasonable reaction rates. Oxygen plants, however, are very expensive to build and operate. This dictates that medium Btu coal gasification plants be constructed with very large capacities to take advantage of economies of scale in order to be competitive.

Because biomass is a distributed resource, transportation costs limit the amount of bionass which can be delivered to a central facility. Consequently biomass gasifiers are limited to a maximum capacity of about 2,000 dry tons of wood per day. Therefore, it is necessary to drastically reduce or eliminate the requirement for oxygen in order to achieve a cost effective process at the smaller scale. Fortunately, biomass is much more reactive than coal and can be gasified at lower temperatures. Less heat is also required for reaction due to 
the higher volatile content. This reduces the oxygen requirement for medium Btu gasifiers that are directiy heated with oxygen. Furthermore, the iower reactor temperatures and heating requirenents make it possible to indirectly heat the biomass in the reactor without using costly and exotic heat exchanger materials, thereby el iminating oxygen requirements altogether. This offers an opportunity for significantly reducing gasification costs. In addition, the $10 \mathrm{w}$ su fur content of most biomass feedstocks makes it possible to gasify biomass in the presence of catalysts without catalyst poisoning problems. The use of catalysts allows for even lower reaction temperatures and makes it possible to adjust the composition of the product gas directly within the reactor to produce synthesis gases for derived liquid fuels. The lower sulfur content also eliminates the need for a costly gas cleanup system to remove sulfur from the product gas.

The goals of the gasification research sponsored by the Bionass Thermochemical Conversion Program are directed toward: 1) deveioping reactor heating methods to eliminate or reduce the requirement for oxygen in medium Btu biomass gasifiers by exoloiting the high reactivity of biomass; and 2 ) to determine the technical feasibility of employing medium Btu gasifiers to produce synthesis ga's for derived liquid fuels. In accordance with these goa 5 , medium Btu gasification technology has been divided into two project areas: Reactor Heating Methods and Synthesis Gas Production, as shown in Figure 4.

The Biomass Thermochemical Conversion Program is currently sponsoring four projects which are investigating reactor heating methods. The Institute of Gas Technology (ICiT) is conducting research 


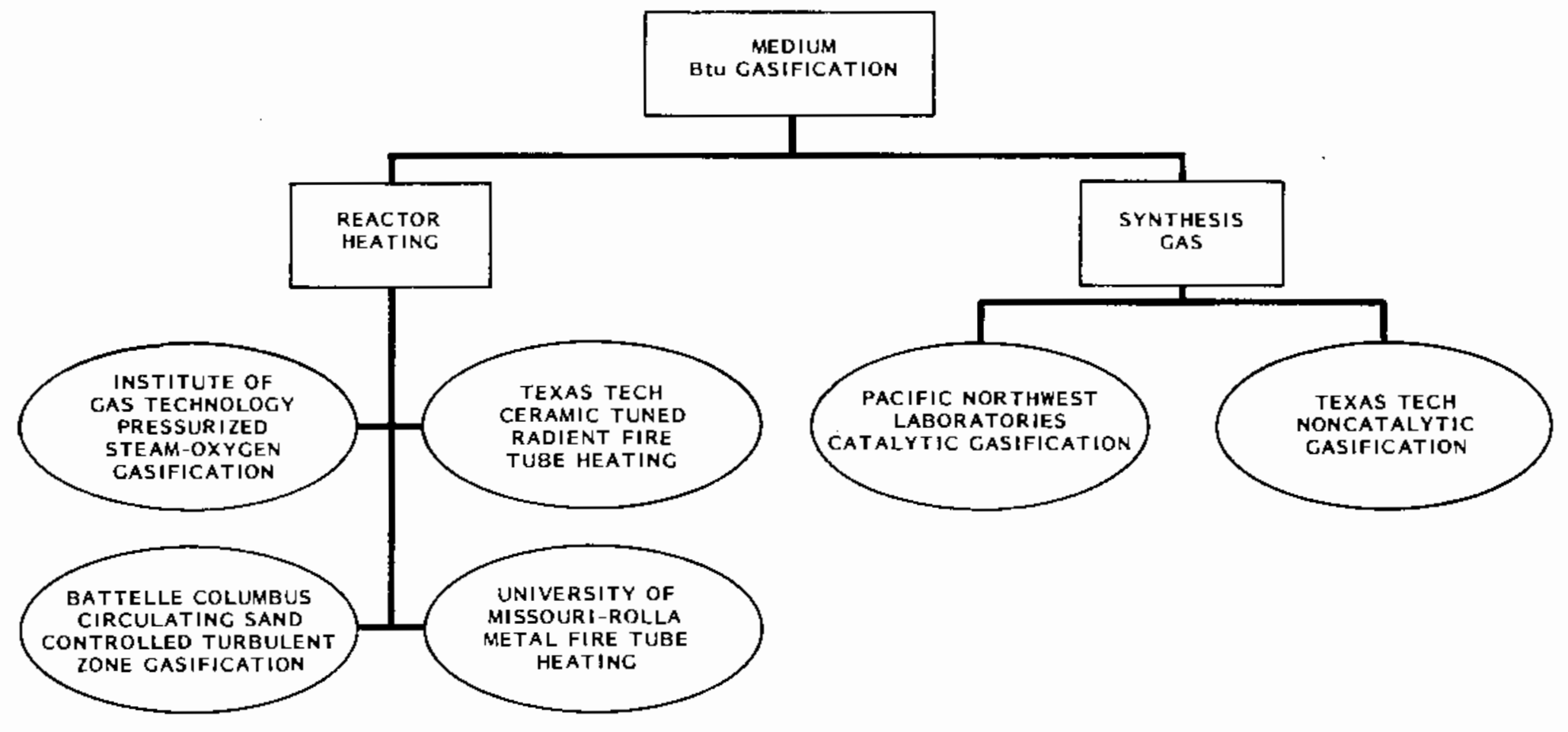

Figure 4. Medium Btu Gasification Research Projects 
to determine the actual oxygen requirements for gasifying biomass to produce a medium Btu gas. IGT has been constructing a flujdized bed research gasifier which is designed to explore the effects of pressure (up to $500 \mathrm{psia}$ ), reactor bed height, feed positions, feedstock type, and temperature on product gas yield and composition.

IGT has also conducted bench scale research to examine the physical and chemical characteristics of candidate feedstocks including Douglas fir, maple, pine and corn stover. Experimients with these species have been performed to evaluate thejr devolatilization and char gasification characteristics. Preliminary results show that the devolatilization of biomass into gases and liquids typically increases only slightly, from 93 percent to 95 percent, for increasing temperatures between $1300^{\circ} \mathrm{F}$ and $1600^{\circ} \mathrm{F}$. The gas yield, however, increases from approximalely 65 percent to 85 percent of dry feed over the same ternperature range due to increased conversion of liquids to gases. These results show the impact of reactor temperature, during devolatilization, on the production of a medium Btu gas.

Char gasification results, shown in Figure 5 , indicate that the gasification rates for the different biomass species were comparable to one another but were nearly 20 times greater than the gasification rates for coal chars. Final analysis of the bench scale data will be used to select operating conditions for the fluidized bed research gasifier.

The University of Missouri - Rolla is conducting a research program to investigate the technical feasibility of using metal fire tubes to provide heat indirectly to a fluidized bed gasifier. In the conceptual design a portion of the feedstock or product gas would be burned to provide heat for the fire tubes. 


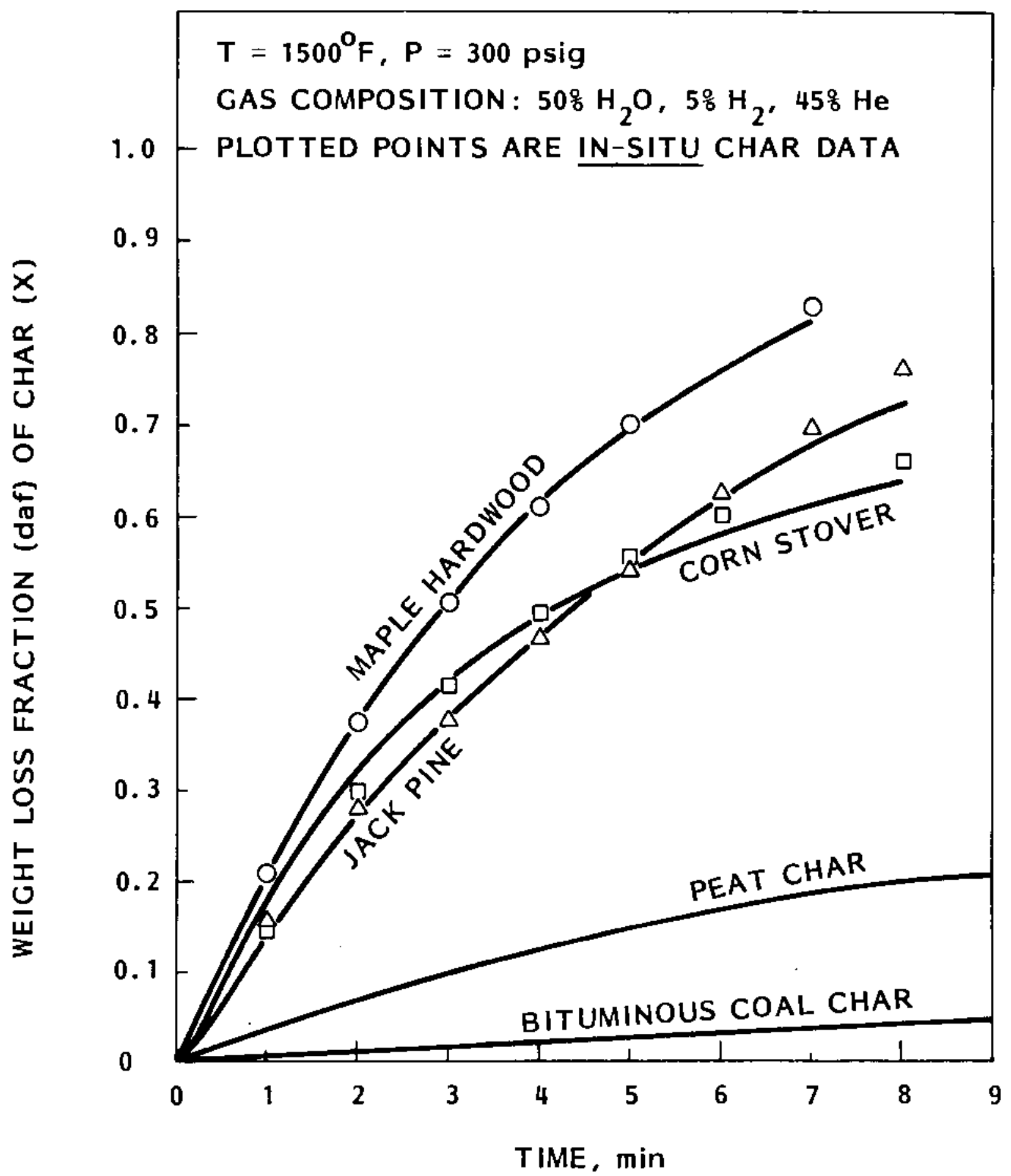

Figure 5. Comparison of Gasification Rates of Various Biomass In-Situ Chars With Those of Peat and Bituminus Coal Chars 
Research at the University has centered on selecting an optimum fire tube configuration which will allow maximum reactor throughput in a fluidized bed research gasifier that will be used to test the concept. Several alternative design configurations were evaluated. The configuration selected for actual testing has 30 one-inch diameter U-tubes spaced using a 2 inch pitch. The design is expected to produce a reactor throughput of $230 \mathrm{ib} / \mathrm{hr}-\mathrm{sq} \mathrm{ft}$ at a bed temperature of $1400^{\circ} \mathrm{F}$. Operation of the indirectly heated gasifier is expected in late 1982.

Texas Tech University is investigating the technical feasibility of enhancing the radiant heat transfer capabilities of indirectly heated fluidized bed gasifiers. The concept uses doped ceramic fire tubes which match the wave length of the heat radiated by the tubes to the absorption wave lengths of the biomass. Figure 6 shows absorption spectra for cellulose, a major component of biomass. By doping the ceramic tubes to emit radiant heat at selecied wave lengths, a large portion of the radiant energy will be absorbed by the biomass, increasing the rate of devolatilization and gasification. Fundamental research at Texas Tech University has been directed toward developing a mathematical model for radiant heat transfer in an absorbing fluidized bed of biomass particles and the development of a kinetic model for biomass pyrolysis in a radiant heating environment. The results of this fundamental research are being used to design a small multiple fire tube reactor for testing the concept under continuous reaction conditions. Battelle-Columbus Laboratories ( $B C L$ ) is conducting research to determine the technical feasibility of indirectly heating an entrained bed gasifier by circulating a low density, hot, incandescent sand to the gasifier. As shown in Figure 7, the entrained sand and any unreacted 


\section{IR ABSORPTION SPECTRUM OF CELLULOSE}

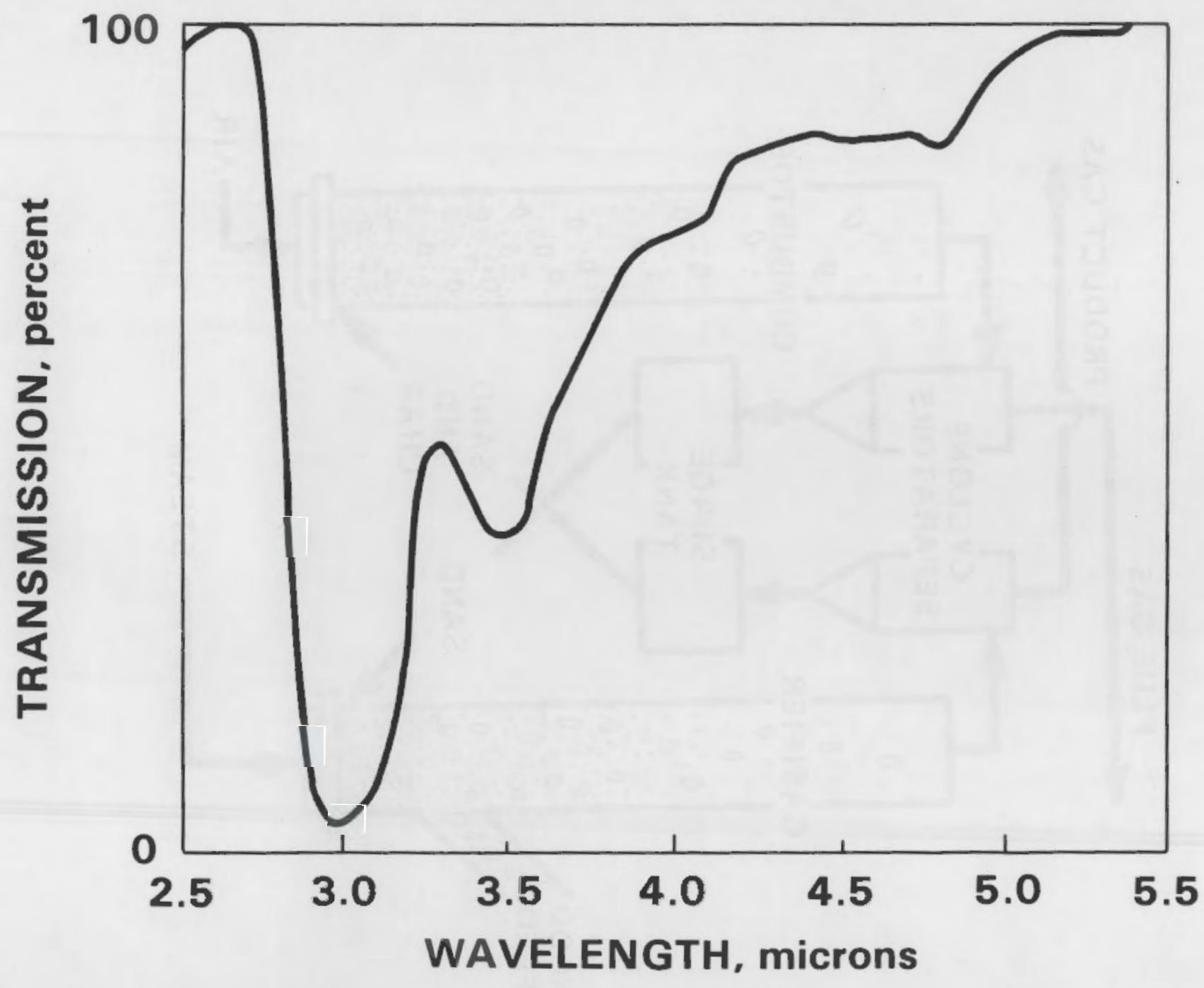

Figure 6. Infrared Absorption Spectrum of Cellulose Fibers [M. Tsuboi, J. Polymer Sci., $25(2), 159-171(1957)]$ 


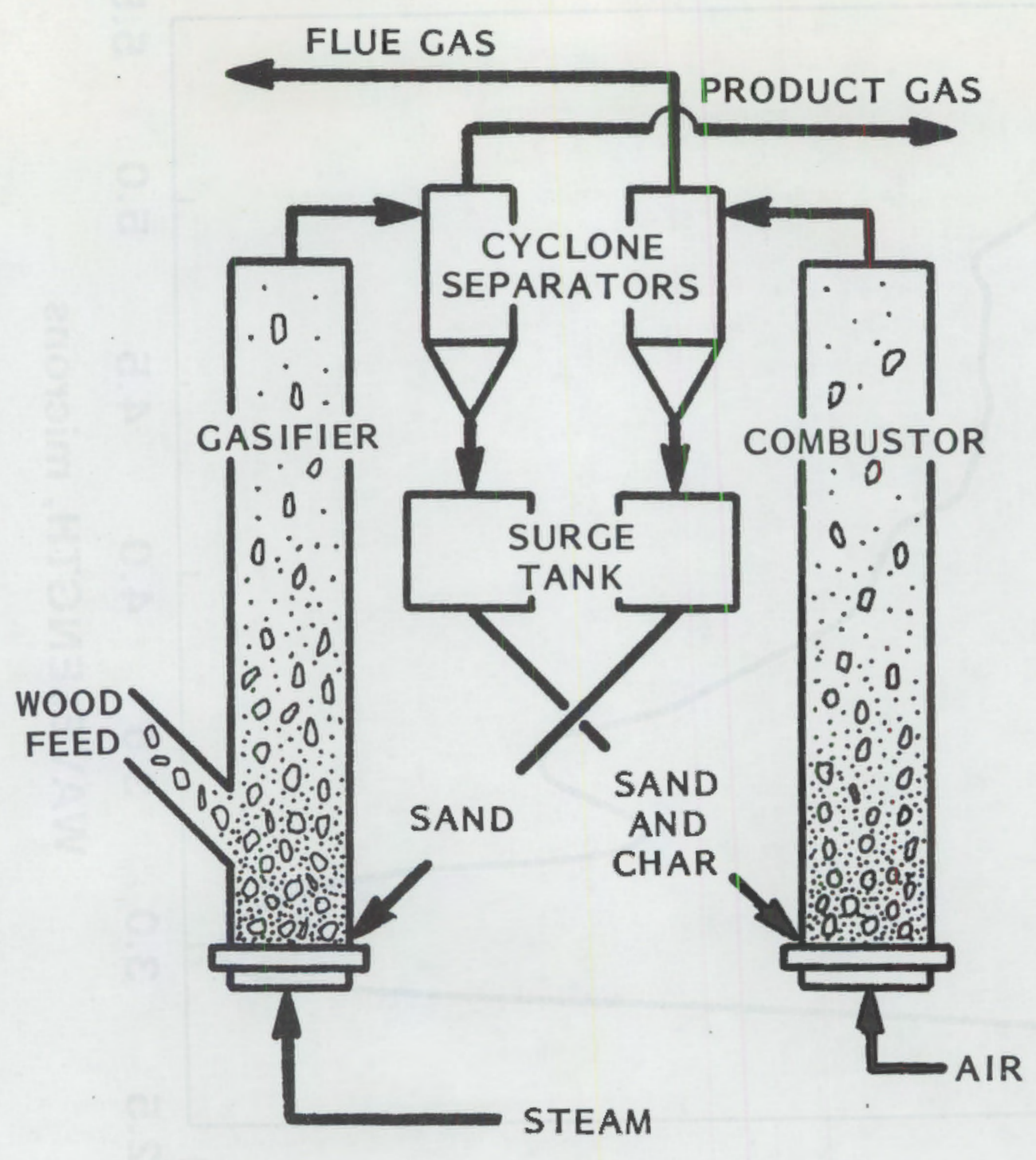

Figure 7. Simplified Process Flow Sheet For Heating Biomass Via Circulating Sand 
char leaving the gasifier is separated from the product gas in a cyclone. Both the sand and char are transferred to an entrained bed combustor where the char is burned with air. The sand is heated to a high temperature and recirculated back to the gasifier.

In previous research sponsored by the Biomass Thermochemical Conversion Program, the $B C L$ gasifier also employed a dense phase of sand in a fluidized bed reactor to aid heat transfer and to help retain the char in the bed at the high steam velocities employed. Recent research during 1982 has shown that reactor internais can be used in place of the dense phase. The reactor internals serve as transport wake inducers, resulting in highly turbulent mixing zones in the reactor. The use of these internals allowed higher reactor temperatures and resulted in drastically improved gas yields, carbon conversions, and throughput for the reactor. Figure 8 compares carbon conversion for the original and modified reactor designs. It can be seen that carbon conversion at the higher temperatures is nearly 90 percent for the modified reactor compared to about 65 percent for the original reactor design. Throughput for the modified reactor has reached as high as $1860 \mathrm{lb} / \mathrm{hr}-\mathrm{sq}$ $\mathrm{ft}$ which is about six times greater than that achieved in conventional fluidized beds and about 80 percent higher than that achieved in the original $\mathrm{BCL}$ reactor design. Research is continuing in order to more fully understand the role of the wake inducers in the gasifier and to more fully explore the operating parameters for the gasifier.

The Biomass Thermochemical Conversion Program is also sponsoring two research projects which are investigating the technical feasibility of producing synthesis gas in a medium Btu gasifier. Synthesis gases for the production methanol and liquid hydrocarbon fuels require 


\section{CARBON CONVERSION TO GAS VS GASIFIER TEMPERATURE}

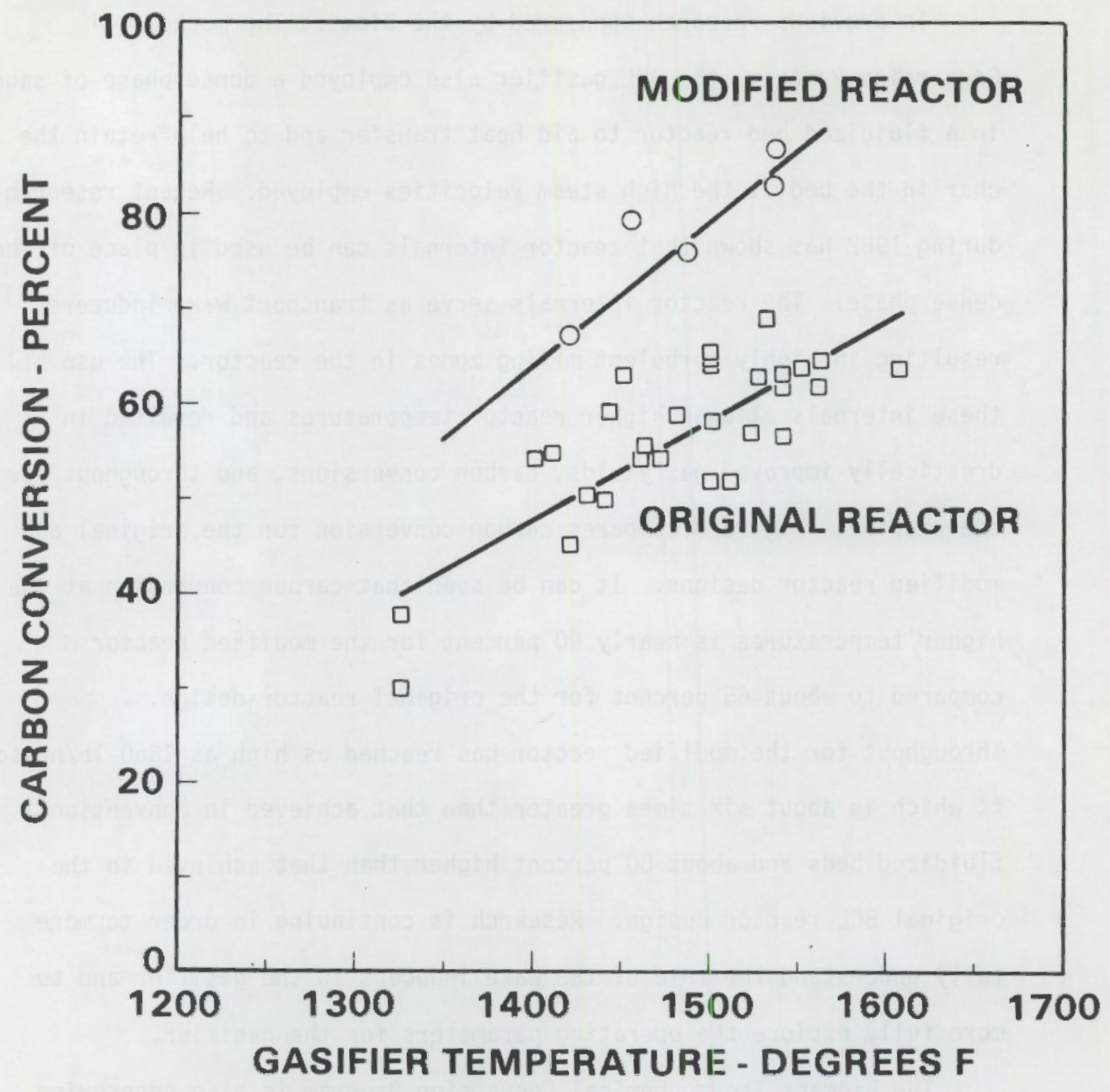

Figure 8. Carbon Conversion Using Circulating Sand to Heat a Biomass Entrained Bed Gasifier 
relatively pure mixtures of hydrogen and carbon monoxide with a molecular ratio of 2.0 to 2.5 moles of hydrogen per mole of carbon monoxide. Texas Tech University has conducted research to determine the technical feasibility of producing a methanol synthesis gas in a gasifier heated with oxygen. Research was conducted in a six inch diameter fluidized bed reactor. The experimental program explored the effects of oxygen feed rate, steam feed rate and solids residence time on the product gas yield and the hydrogen to carbon monoxide ratio in the product gas. A correlation was developed based on the experimental results and was used to estimate the optimum operating conditions for producing a methanol synthesis gas. Texas Tech concluded that an oxygen to dry feed ratio of $0.35 \mathrm{~kg} / \mathrm{Kg}$ feed, and a steam to dry feed ratio of $0.9 \mathrm{~kg} / \mathrm{Kg}$ feed would produce an acceptable hydrogen to carbon monoxide mole ratio of 2.0 .

Pacific Northwest Laboratory has been conducting research to produce a methanol synthesis gas in a fluidized bed gasifier, utilizing various catalysts as the fluidizing medium. Bench scale studies have identified a $\mathrm{Ni}-\mathrm{CO}-\mathrm{Mo} / \mathrm{SiO}_{2}-\mathrm{Al}_{2} \mathrm{O}_{3}$ catalyst for the generation of methanol synthesis gas that has proven to be resistant to deactivation. Research using a six inch diameter fluidized bed gasifier, shown in Figure 9, demonstrated the technical feasibility of producing a synthesis gas with a hydrogen to carbon monoxide mole ratio exceeding 2.0 . The fluidized bed gasifier has recently been modified to explore the effect of pressures up to 150 psia on the gasifier performance. Experiments are being conducted using the pressurized gasifier to determine whether the overall biomass to methanol process can be made more efficient by eliminating a portion of the compression requirements for the methanol synthesis reaction without adversely affecting the gasification process. 


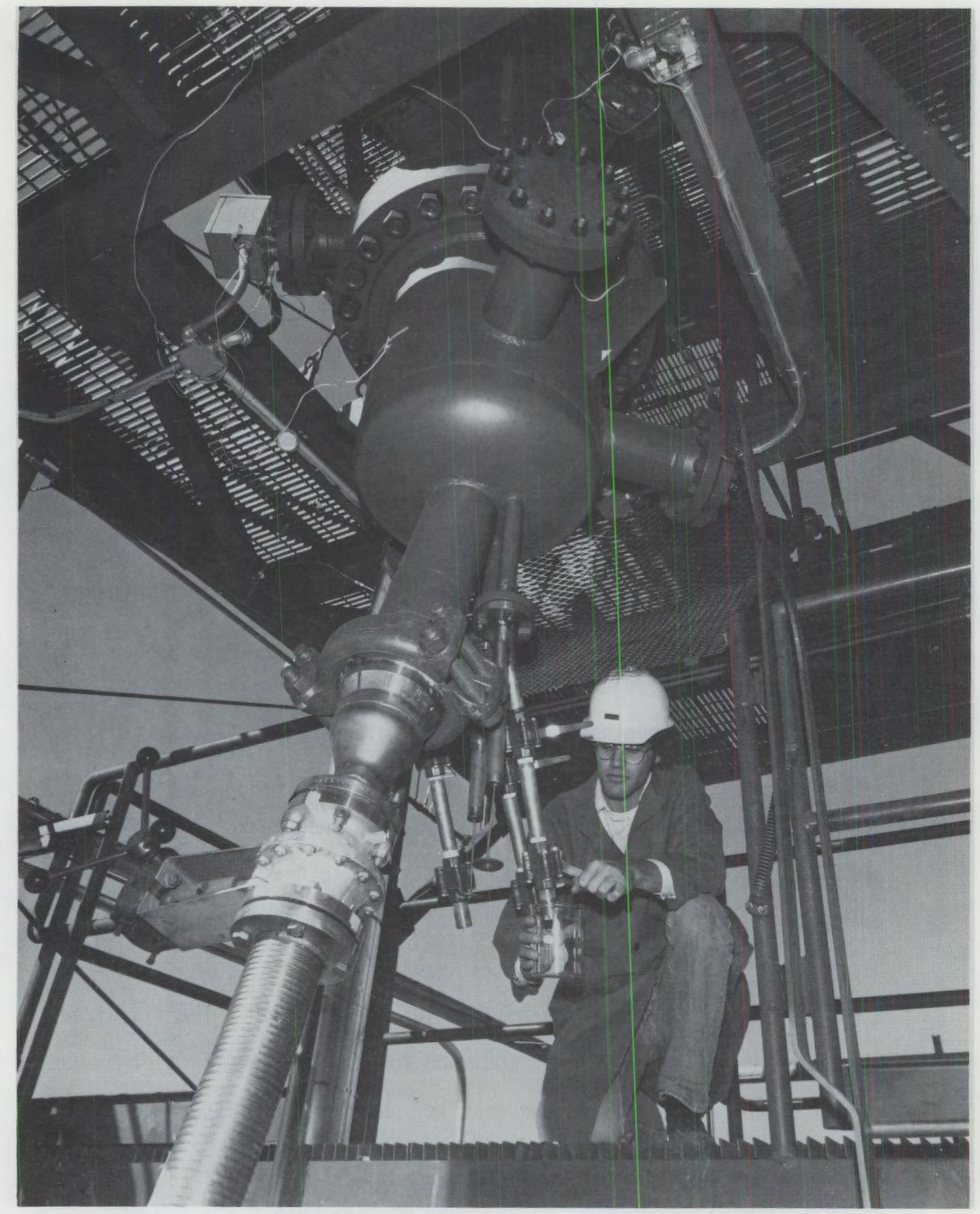

Figure 9. Bottom View of 6-Inch Diameter Fluidized Bed Gasifier at Pacific Northwest Laboratory 


\section{PYROLYSIS TECHNOLOGY}

The term pyrolysis refers to the thermal decomposition of biomass in an oxygen-free environment. Traditionally, pyrolysis has been used as an age old process to produce charcoal. Conventional pyrolysis typically produces products consisting of about one third each gases, pyrolysis oil, and solid char. The process is inefficient since large quantities of low value liquids and gases are formed in addition to desired solid products. Batchwise, often primitive, conversion units have also added to the inefficiency of conventional pyrolysis processes. Although research such as that on the nearly commercial Tech Air process has been done to improve efficiencies, pyrolysis processes were limited to conventional products until about 10 years ago.

In recent years, the Biomass Thermochemical Conversion Program has played a major role in advancing the concept of rapid pyrolysis into a promising, state-of-the-art research area. Of major significance was research on the rates of heating during biomass pyrolysis. Using rapid heating rates, yields of gases and liquids as high as $95 \%$ can be produced. These products contain up to about $20 \%$ high value olefinic products such as ethylene and BTX (benzene, toluene, and xylene). These high value products are potentially useful as fuels, octane enhancers, and petrochemical feedstocks.

During 1982, the Thermochemical Conversion Program sponsored six basic research projects in the area of biomass pyrolysis, as shown in Figure 10. The objective of this work is to investigate the phenomenon of rapid pyrolysis in order to develop a fundamental data base for this 


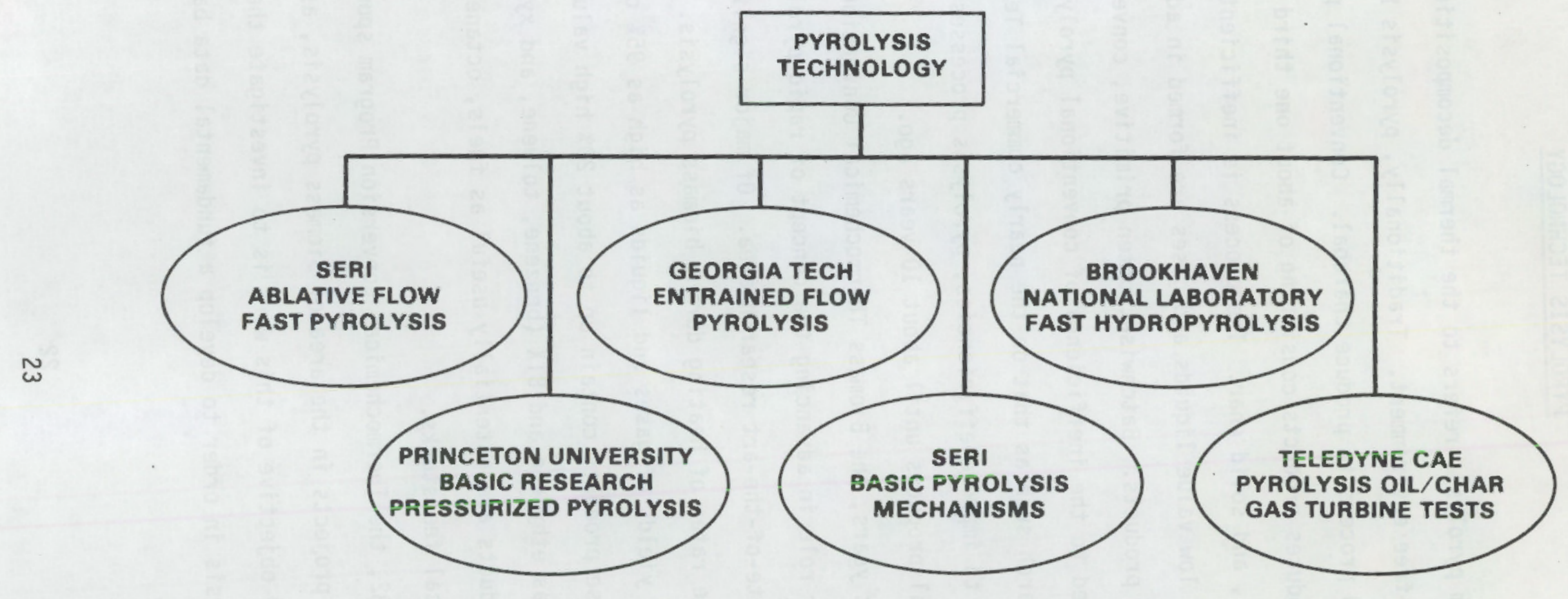

Figure 10. Pyrolysis Research Projects 
promising research area. Specific goals include:

- Elucidation of reaction pathways during rapid pyrolysis

- Examination of methods for achieving high heat fluxes in rapid pyrolysis systems

- Examination of liquids production via rapid pyrolysis

- Determination of the effects of pressure on biomass pyrolysis

- Determination of the effects of reactive atmospheres on rapid pyrolysis products and yields, and

- Determination of pyrolysis oil combustion characteristics.

The Solar Energy Research Institute (SERI) is conducting two projects investigating the fast pyrolysis of biomass. In the first project, basic research on the mechanisms involved in fast pyrolysis is being conducted. Using a molecular beam mass spectrometer, a detailed picture of the individual, sequential reaction steps occurring during fast pyrolysis is being developed by measuring the change in product spectrum occurring during millisecond intervals. A schematic of the mass spectrometer is shown in Figure 11. During 1982, the primary pyrolysis products from a number of celluloses were surveyed. Major findings include the observation that the higher mass components appear to evolve nearly simuitaneously during decomposition. This may reflect the fact that the cellulose "unzips" and dehydrates on a very short time scale compared to the total time of the rapid pyrolysis. Such evidence is important to understanding fundamental reaction mechanisms in fast pyrolysis.

The second project at SERI is investigating the use of an ablative reactor for fast pyrolysis. The objective of this work is to maximize yields of high value olefins and other products such as benzene, toluene, and xylene which are formed under conditions of very rapid 


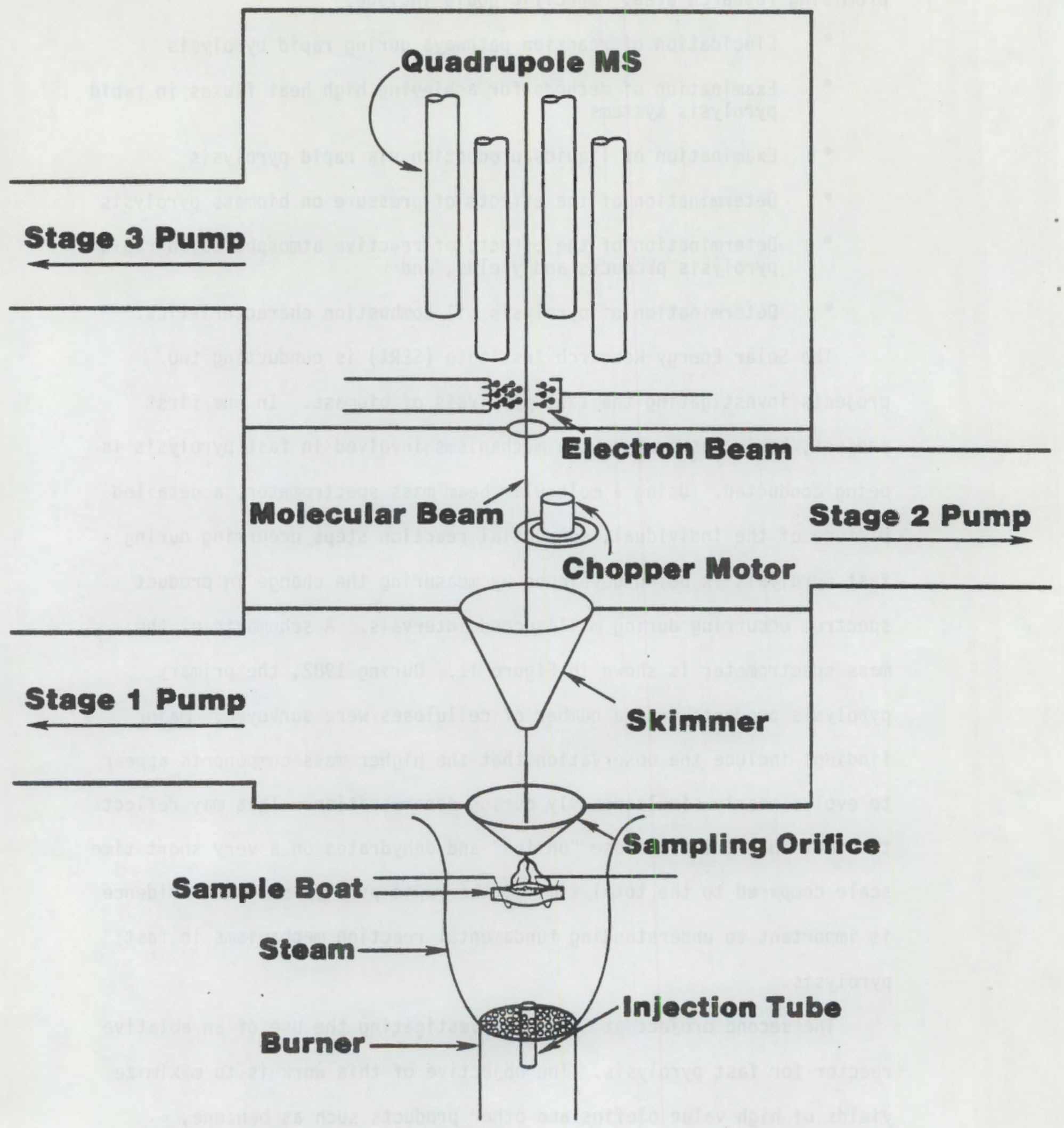

Figure 11. High Pressure Molecular Beam Sampling System to be Used With a Fast Pyrolys is Reactor 
pyrolysis. The goal of this research is to determine how to obtain the high heat fluxes needed for rapid pyrolysis and to investigate fundamental reaction behavior. The unique reactor supplies heat for reaction by the ablation of biomass particles forced against a hot reactor wall. Heatup rates of up to $500,000^{\circ} \mathrm{C} / \mathrm{sec}$ can be obtained at the sample surface. Contact of the biomass with the reactor surface converts the biomass into a liquid layer which subsequently is vaporized. A schematic of the reactor system is shown in Figure 12, and the reactor itself is shown in Figure 13.

During 1982, SERI made progress both in improving the ablative pyrolysis reactor efficiency and in determining key operating parameters. Initially, channeling of the biomass feedstock stream in the ablative reactor reduced heat transfer efficiency. Insertion of a helical coil down the length of the reactor directed the feedstock into a longer path length and increased heat transfer efficiencies. Data collected during experimental operation also showed that high steam to biomass ratios in the feedstock injection stream were unnecessary. Lowered steam requirements should improve the economics of olefin production in this type of system.

Brookhaven National Laboratory is conducting research on the rapid pyrolysis of biomass in reactive atmospheres. The goal of this work during 1982 has been to examine fundamentals of biomass pyrolysis in atmospheres of both hydrogen (hydropyrolysis) and methane (methanopyrolysis). The pyrolysis reactor at Brookhaven is shown schematically in Figure 14. Performed at pressures of 50-500 psi and temperatures of $800-1000^{\circ} \mathrm{C}$, hydropyrolysis has been found to yield carbon monoxide, methane, ethane, and BTX as major products. Total 


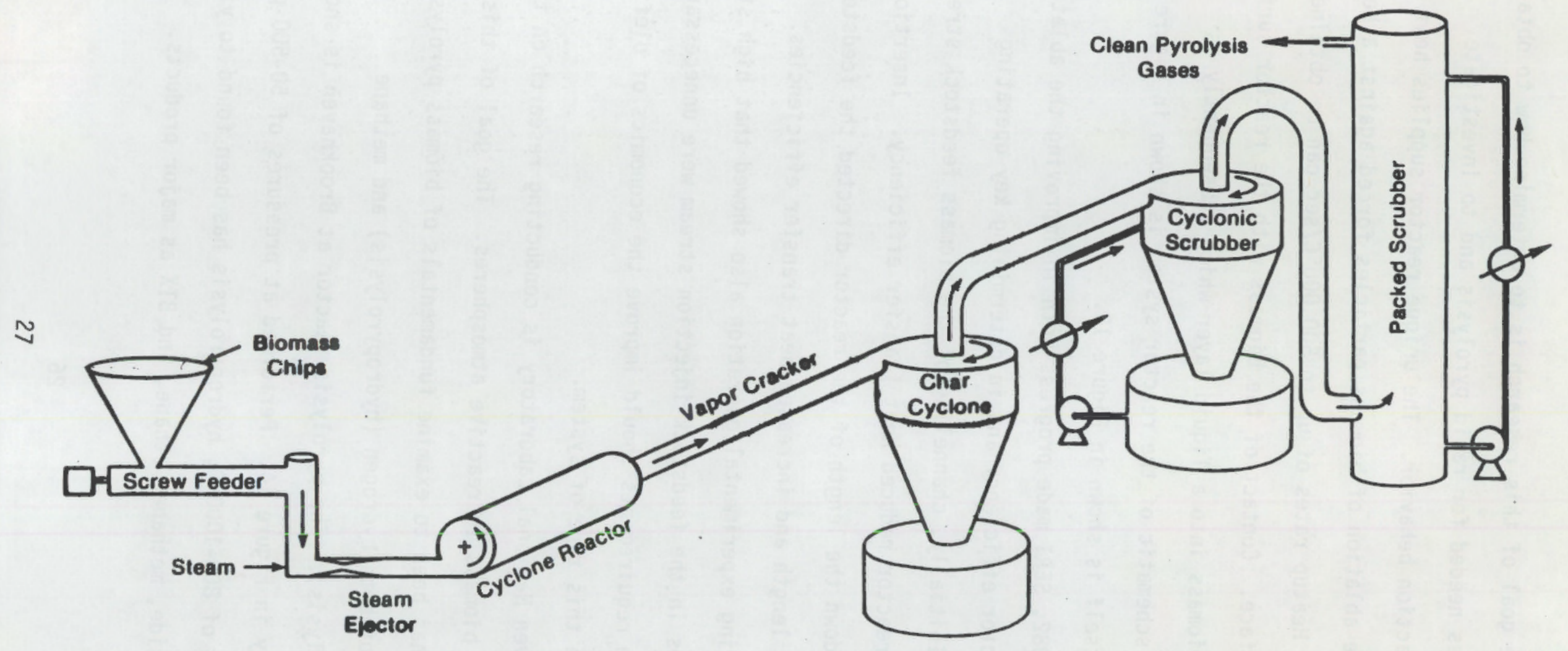

Rapid Pyrolysis Test Reactor - SERI

Figure 12. Schematic Diagram of Entrained Flow, Ablative Pyrolys is Reactor 


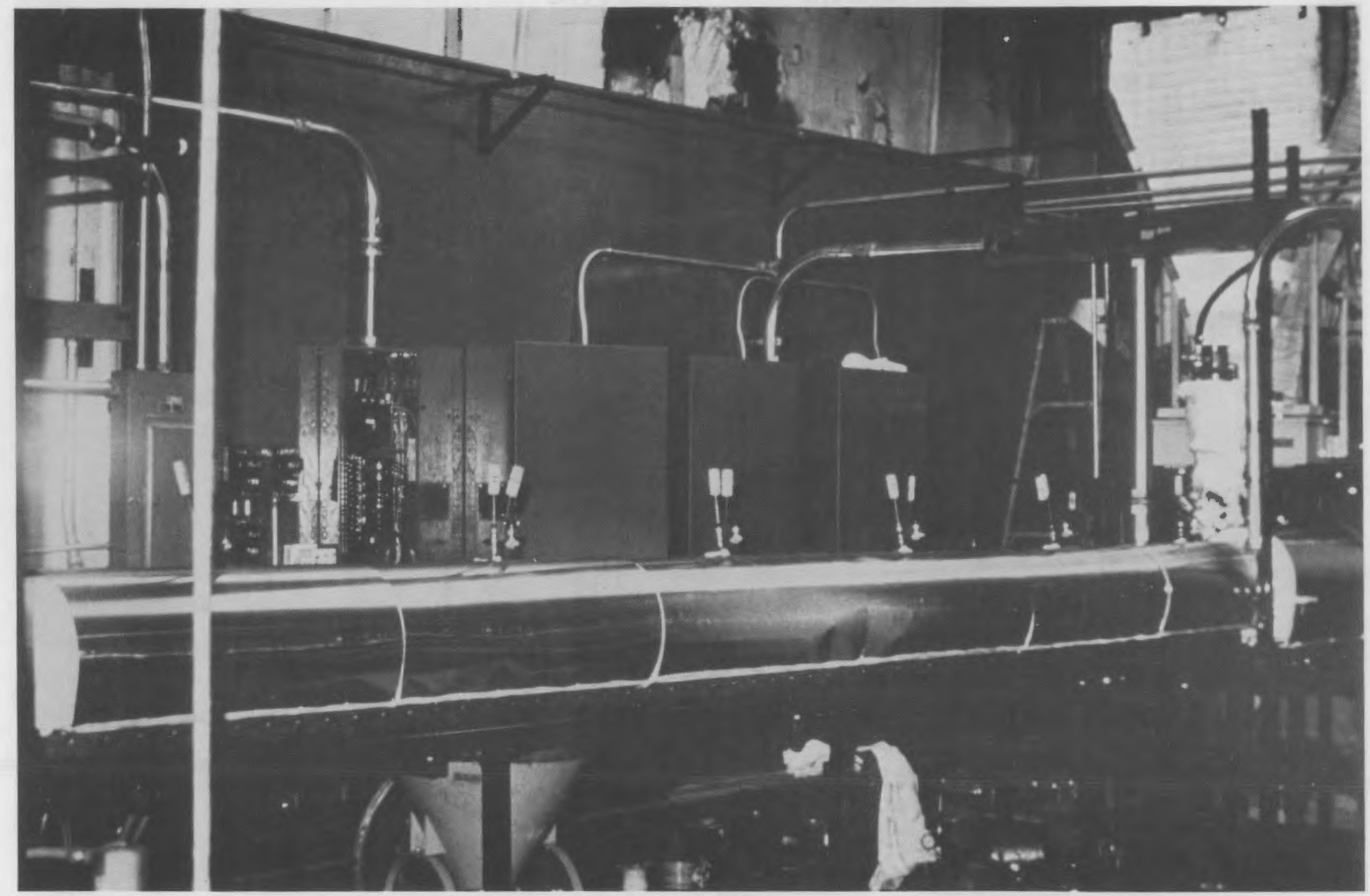

Figure 13. Ablative Pyrolysis Reactor Showing Feed Hopper and Reactor at the Rear, Vapor Cracker with Thermocouples, and Steam Generator (Parallel to Vapor Cracker) 


\section{SCHEMATIC FLOWSHEET OF BROOKHAVEN PYROLYSIS EXPERIMENT}

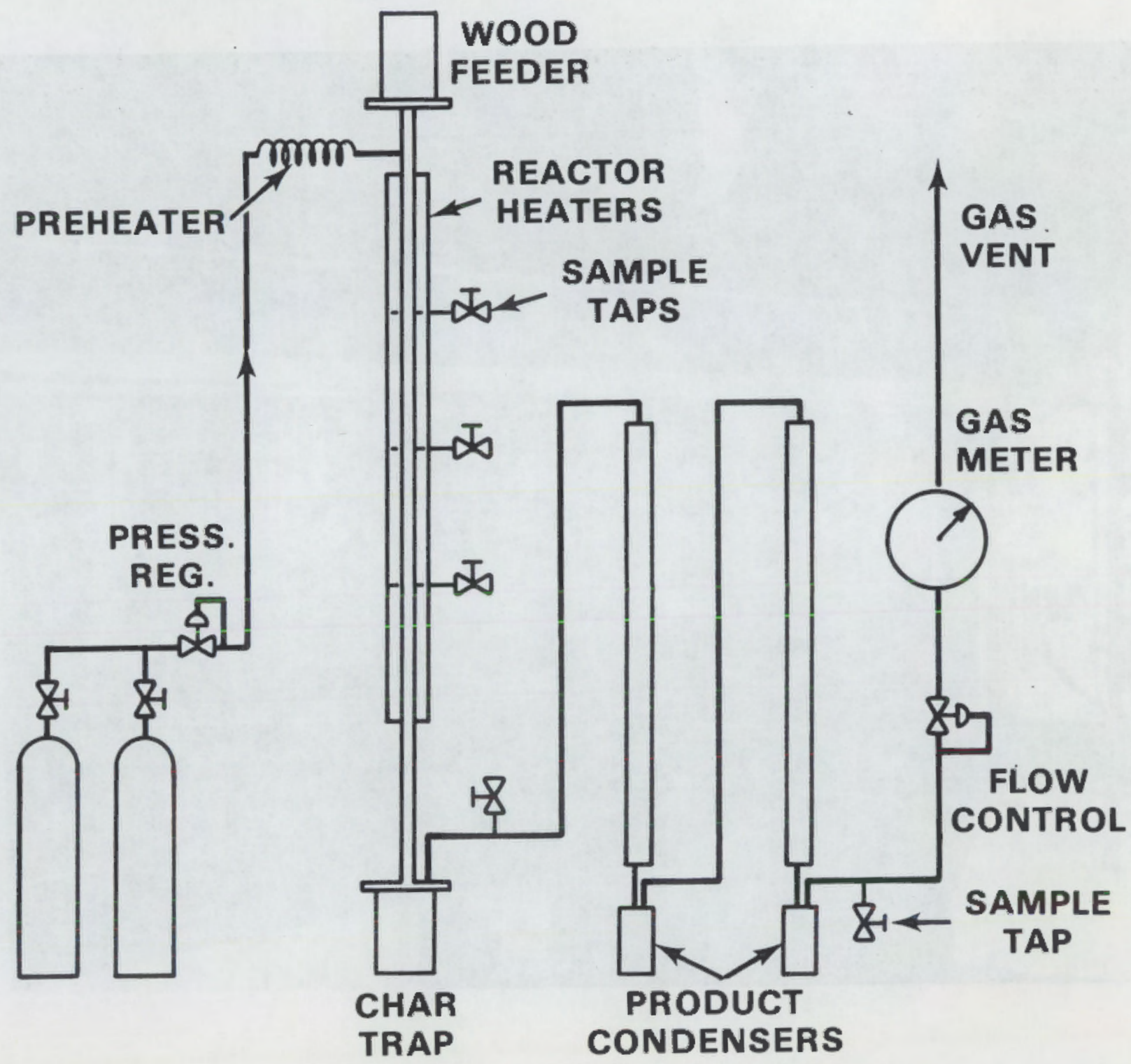

Figure 14. Schematic Diagram of Fast Pyrolys is Reactor at Brookhaven National Laboratory 
carbon conversions of over 95\% are obtained. Brookhaven also discovered that methanopyrolysis leads to a quite different product slate. Major product yields included over $20 \%$ olefins and $10 \%$ BTX products for reactions at $1000^{\circ} \mathrm{C}$. These yields are about double those achieved in inert atmospheres. This result is surprising since methane is not reactive under otherwise identical conditions when biomass is absent. Further research is currently being conducted to resolve the origin of this phenomena since the conversion of biomass to these high value products has positive implications for conversion economics.

Effects of pressure on biomass pyrolysis were investigated during 1982 in a project at the University of Hawail. Using a special differential scanning calorimeter, heats of reaction for biomass pyrolysis were measured as a function of pressure. Experimental results showed that both anhydrocellulose and levoglucosan (intermediate products of the primary competitive reactions in cellulose hydrolysis) underwent subsequent competitive reactions. This information has allowed the proposed pyrolysis mechanism for cellulose to be expanded as shown in Figure 15.

Research in entrained rapid pyrolysis was also performed during 1982 at Georgia Institute of Technology. The overall goal of this research is to use rapid pyrolys is to generate products which are primarily liquids. Through 1982, design and construction of an entrained pyrolysis reactor was conducted. Rapid heat-up of the biomass feedstock in the entrained flow reactor is expected to result in pyrolysis oil yields of approximately $60 \%$ by weight. Fundamental studies on biomass pyrolysis were also perfomed to obtain necessary basic information on kinetic and thermodyramic parameters. Liquid 


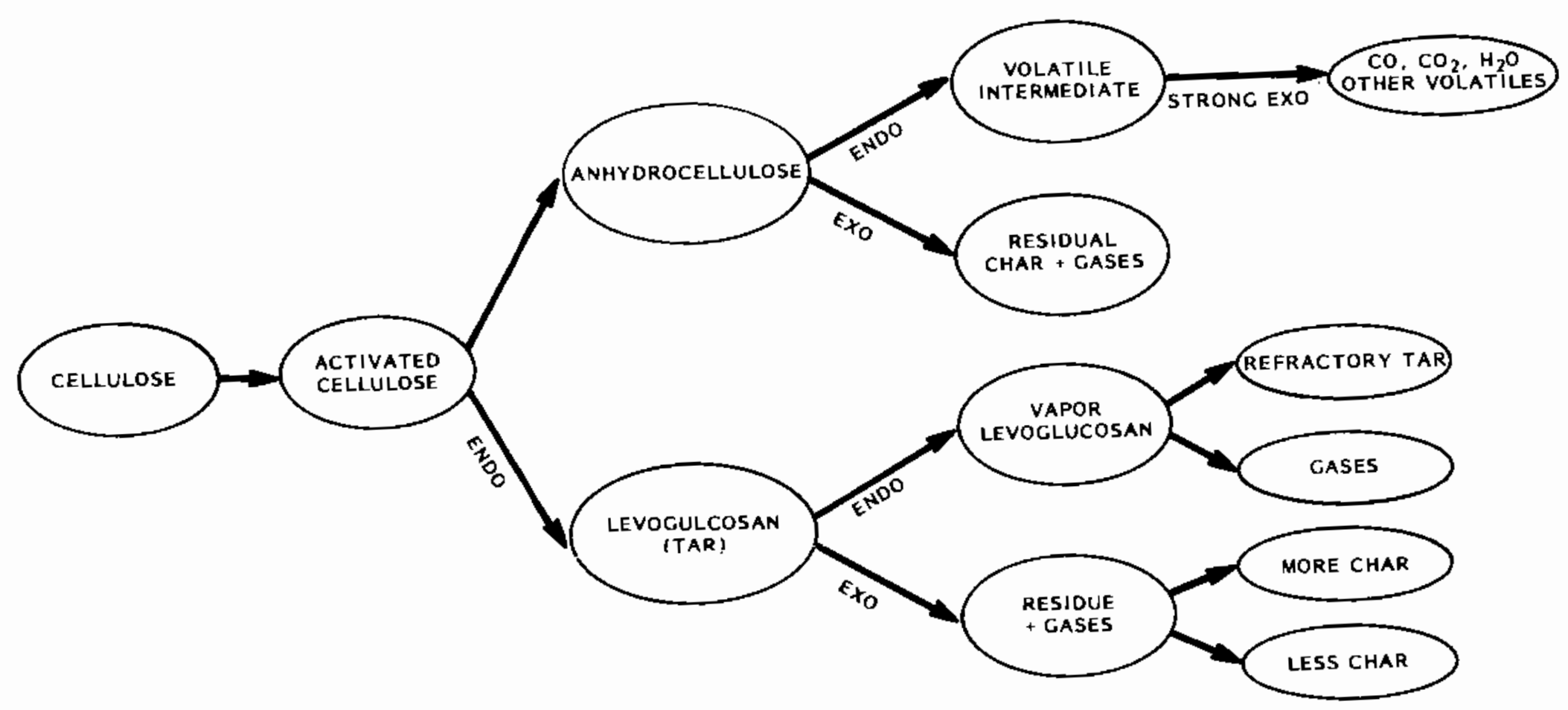

Figure 15. Competitive Reaction Mechanisms Proposed for the Pyrolysis of Biomass 
product yields doubled in going from a batch wise reactor to a rotating tubular reactor which more nearly resembles entrained flow. These results support the possibility of obtaining large liquid yields in a cost effective manner from these types of systems.

Teledyne CAE has conducted research to determine the technical feasibility of burning biomass derived pyrolytic oil in a direct fired gas turbine. Combustion experiments were cunducted using a test rig to simulate the combustion chamber of a $J 69$ gas turbine engine. Other experiments were conducted to evaluate the effect of hot pyrolytic oil on the turbine fuel system materials of construction.

Teledyne concluded that pyrolytic oil could be burned in the 369 combustor with a combustion efficiency approaching 95 percent, which compares favorably with a combustion efficiency of 99 percent for JP-4 jet fuel. A fuel mixture containing equal parts of JP-4 and pyrolytic oit had a combustion efficiency of 99 percent. This suggests that pyrolytic oil may serve as an excellent supplement to JP-4 and possibly other petruleum fuels. Combustion tests using an $85 \%$ pyrolytic oil, $15 \%$ char mixture were unsuccessfur due to the loss of combustion stability and subsequent blow out of the combustion flame. This suggests that char will probably be unsuitable as an additive to pyrolytic oil.

It was also found that hot pyrolytic oil causes damage to nonmetalic components and low alloy steels found in turbine fuel systems, due to its acidic nature. Consequently it may be necessary to protect fuel system materials from acidic attack if pyrolytic oil is to be used as a fuel in this type of turbine. 


\section{DIRECT LIQUEFACTION TECHNOLOGY}

The Biomass Thermochemical Conversion Program is sponsoring research on the direct liquefaction of biomass. Direct liquefaction is defined in the broadest sense as any thermochemical conversion process which produces liquid products from biomass feedstock without going through a separate intermediate gas phase. Over the past few years, however, this terminology has become more narrowly defined to describe a particular type of reductive iquefaction. In this direct liquefaction research, biomass siurries are heated to moderate temperatures at high pressures with a catalyst in a reducing atmosphere of carbon monoxide and hydrogen.

The goal of the direct liquefaction program is to produce liquid products which could be used as substitutes for Nos. 2 and 6 fuel oils, and distillate fractions which could potentially be used for diesel fuels, octane enhancers, and other related uses. The liquefaction products have greater energy densities than the original bionass feedstock and can be readily transported. Liquid fuels have traditionaliy played a major role in the United States energy demand picture, and liquid products from biomass could be used directly for current liquid fuel needs without requiring major retrofit of existing equipment. The potential use of such liquid products, after some upgrading, as fuel extenders or substitutes also provides a possible source of transportation fuels which could contribute to national emergency preparedness.

During 1982, the main emphas is of DOE sponsored research in direct liquefaction has been focused on basic aspects of the liquefaction 
process. Projects sponsored in the area of direct liquefaction during 1982 are shown in Figure 16 . The primary goal of this research has been to evaluate the technical feasibility of existing process concepts and to conduct research on new concepts which could lead to major technical advances in the field of direct liquefaction. This research includes examination of alternative catalysts systems and examination of advanced concepts for liquefaction reactor systems. In addition to this research, a final report from the multi-jear operation of the Albany, Oregon, Biomass Liquefaction Facility was completed.

To date, research in direct liquefaction has been based on two primary process alternatives. The first is a concept initially proposed in work at the Pittsburgh Energy Research Center (PERC) and the second includes modifications originally suggested by Lawrence Berkeley Laboratory (LBL). Both concepts were previously tested at the Albany, Oregon Biomass Liquefaction Facility and have formed the basis for current research thrusts.

The PERC direct Tiquefaction flowsheet was based on a series of batchwise, bench scaie bjomass conversion experiments conducted by the Pittsburgh Energy Research Center of the U.S. Bureau of Mines in the early 1970's. In this flowsheet, bjomass flour is mixed with recycle wood oil and sodium carbonate catalyst along with a reducing gas of $\mathrm{H}_{2} / \mathrm{CO}$ mixtures. The mixture is injected into a high pressure vessel (3000 psi) and heated to about $350^{\circ} \mathrm{C}$. The product stream is cooled and flashed into a pressure let-down vessel. The oil phase product is withdrawn and part of it is recycled for use! as slurry medium.

In the alternate LBL process flowsheet, wood is first prehydrolyzed with dilute sulfuric acid to form a pumpable aqueous siurry. The 


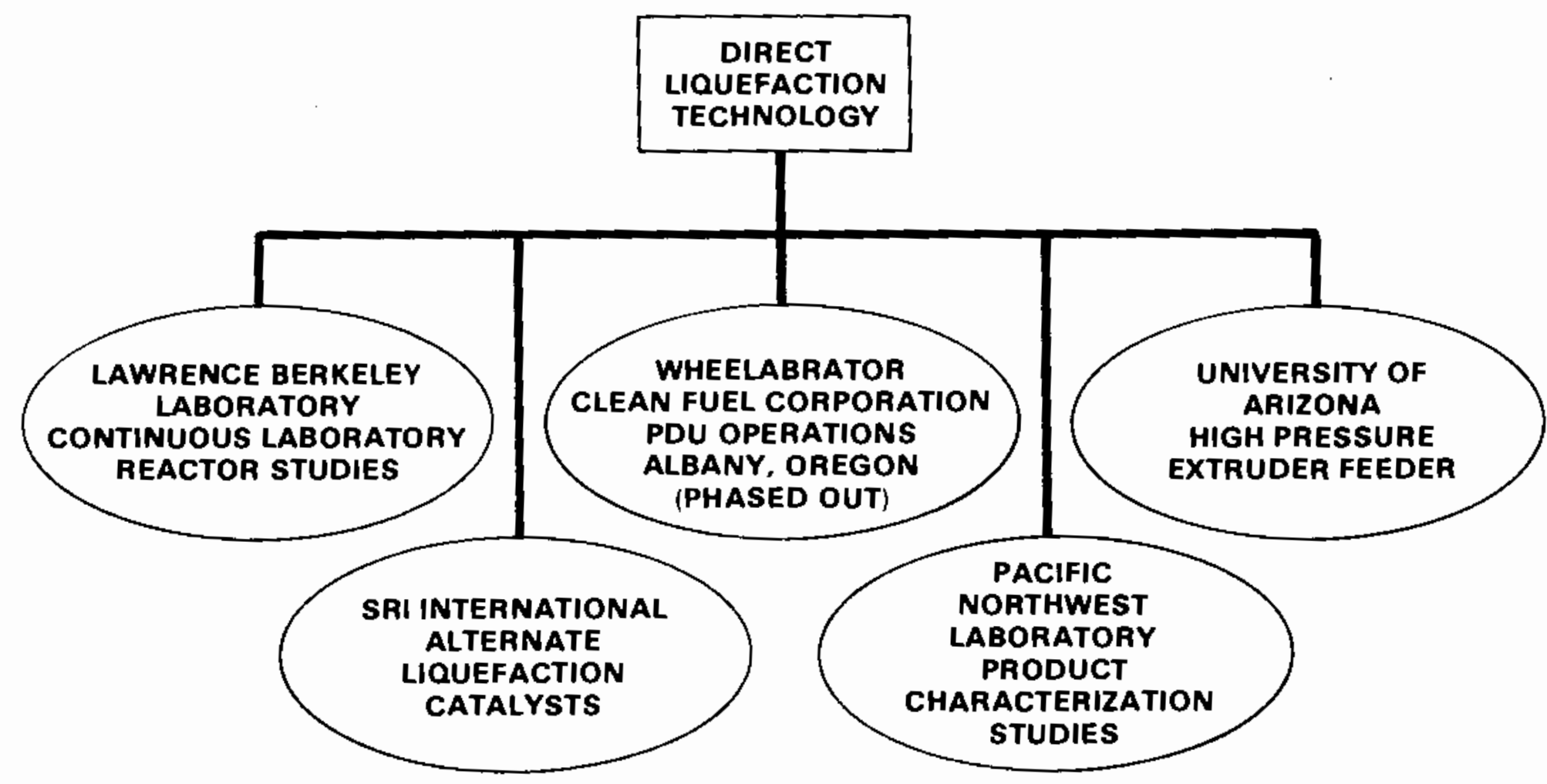

Figure 16. Direct Liquefaction Research Projects 
aqueous slurry is then mixed with sodium carbonate catalyst and reducing gas and injected into the high pressure vessel. After reaction and pressure let-down, the product oil is separated from the aqueous phase.

At Lawrence Berkeley Laboratory, research during 1982 has been centered on developing a more complete understanding of the aqueous phase (LBL) Tiquefaction process. The goal has been to gain fundamental information about effects of process variables on product yields and quality. The research uses a bench scale, contiriuous reactor which is shown schematically in Figure 17. Research results show that either $\mathrm{H}_{2}$, CO, or mixtures of both may be used as the reducing gas with littie difference in this system. These results indicate that costly, high purity reducing gases would not be required.

The research results also point out cifferences between the oil slurry and aqueous slurry processes. In the aqueous slurry process, approximately $25 \%$ of the biomass feedstock is converted to water solubie products during the conversion. Analysis at LBL has shown that these products consist largely of low value acids including acctic, and propionic acids. These products are difficult to separate from the aqueous phase and reduce the overall yieid of oil products as compared to the oil siurry (PERC) process. As a result, it appears that the aqueous phase process may be best suited to wet feedstocks where the loss in product yield is made up by reduced drying requirements. The research team at LBL has also succeeded in developing a gradjent elution techrique which is very useful in separating the liquefaction products into several fractions. 


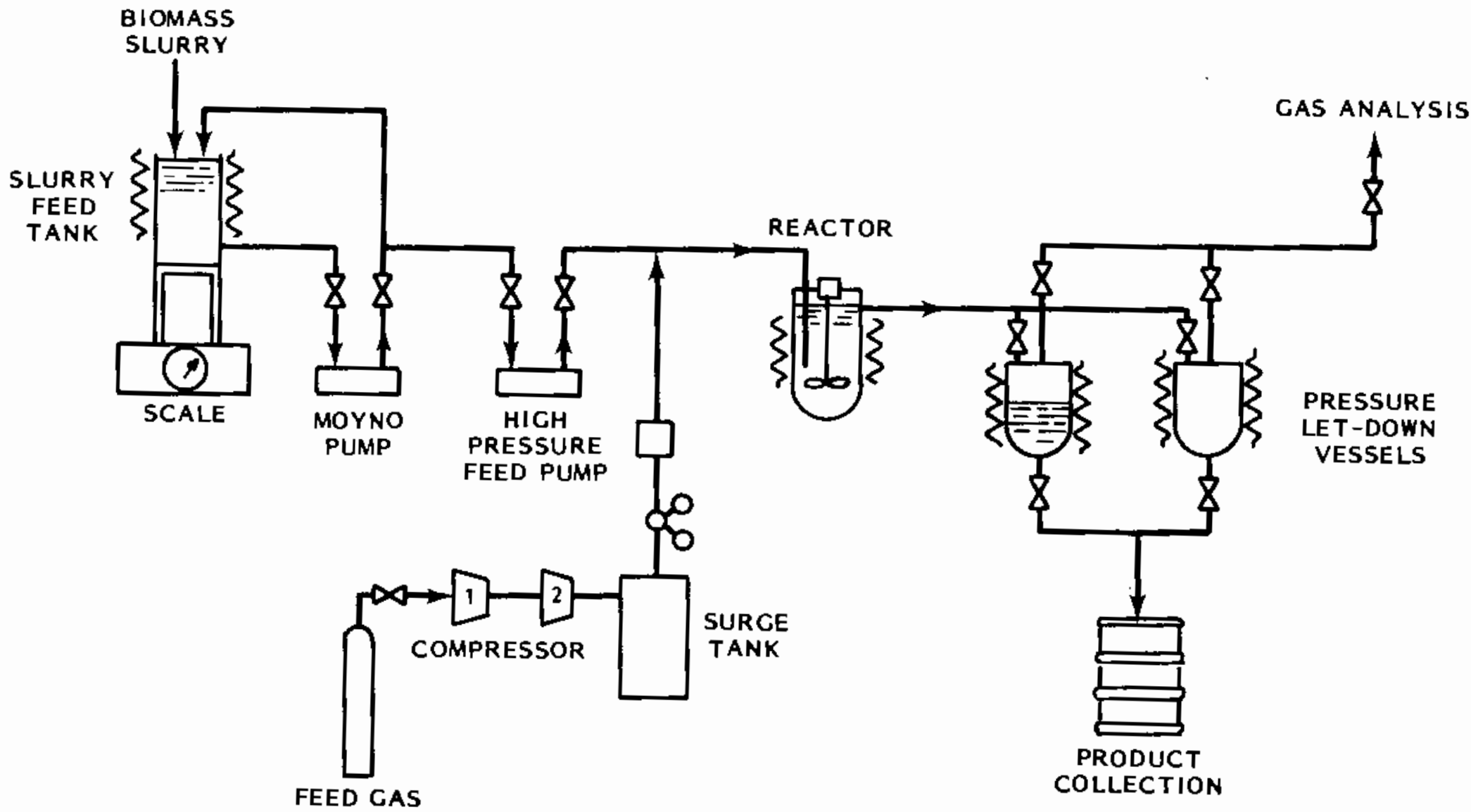

Figure 17. Schematic Diagram of the Bench-Scale Continuous Direct Liquefaction Reactor at Lawrence Berkeley Laboratory 
Research on improved catalysts for biomass direct liquefaction was performed in 1982 by SRI International. The goal of this work was to examine a wide range of soluble, homogeneous salts for improved catalytic activity in the aqueous siurry (LBL) process. In total, fifteen transition metal salts were tested for activity in batchwise autoclave experiments. Of the meta? iors tested, eight showed varying degrees of catalytic activity with potassium tetracyanonickelate being the most active. While this catalyst may not be economicaliy feasible on a commercial scale, further in-depth studies revealed interesting mechanistic data on the invoivement of the catalyst during the iiquefaction reaction. These studies suggest that the metal ion is particularly important as a hydrogenation catalyst and that the attached cation is involved in the formation of formate. Understanding the fundamental reaction mechanisms should lead to additional progress on alternative catalysts.

Research on advanced concepts for direct liquefaction was performed in 1982 by the University of Arizona. The goal of this work has been to adapt a modified extruder for pumping very concentrated, viscous biomass siurries in the oil recycle (PERC) process. The extruder/feeder system is shown schematically in Figure 1B. The modified extruder/feeder system has now been shown to be capable of handing slurries as concentrated as $60 \%$ wood solids ir biomass oit. Conventional systems typicaliy cannot handle slurries containing over about 25\% wood. During 1982, the University of Arizona completed experimental work and detailed engineering analysis to evaluate the potential for using the extruder/feeder in an actual liquefaction system. The analysis showed that the extruder/feeder would potentially offer advantages over other 


\section{EXTRUDER/FEEDER SYSTEM}

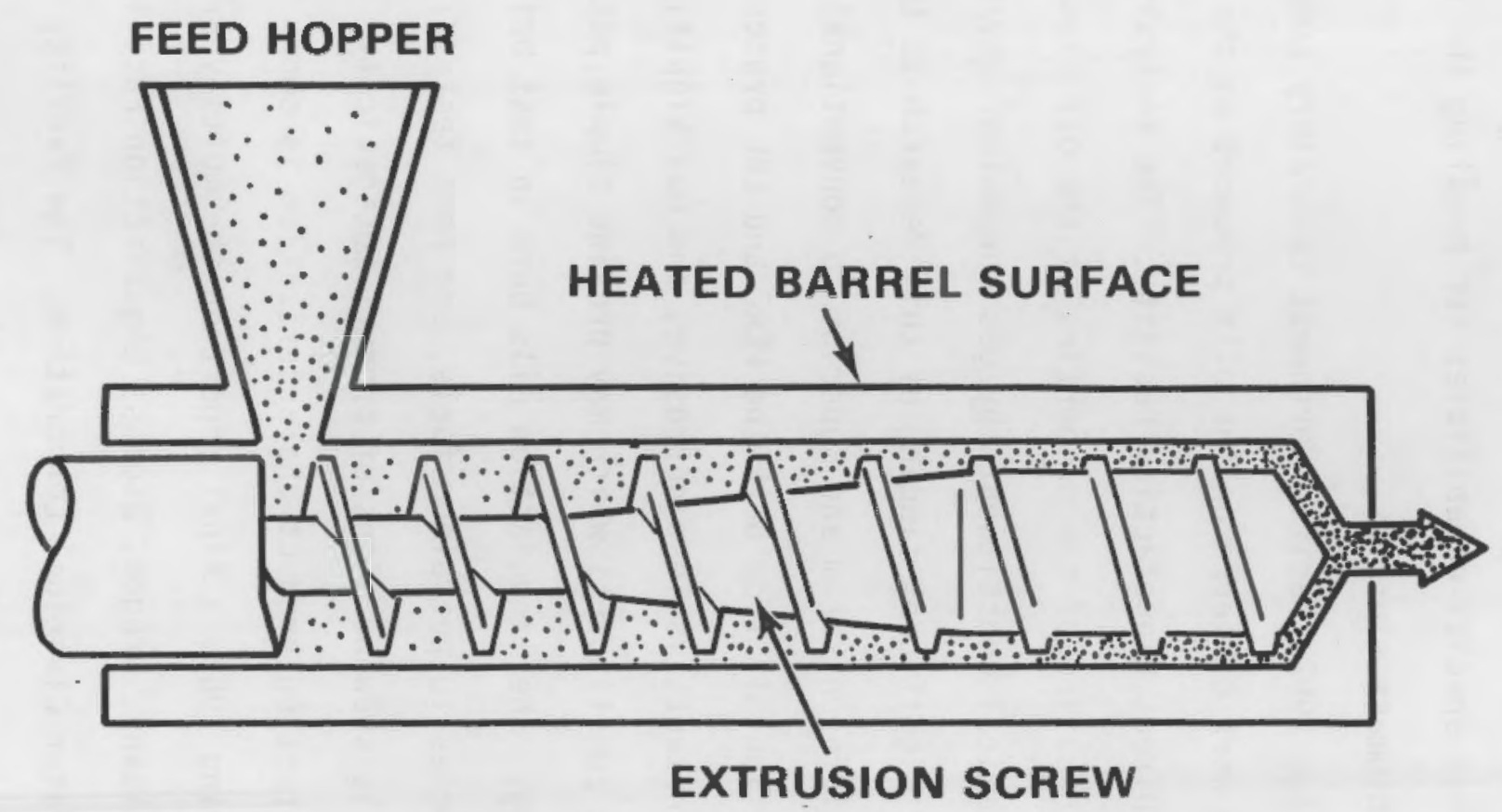

Figure 18. Extruder/Feeder System for Pumping Concentrated Biomass Slurries 
systems by reducing overall energy requirements and by increasing throughput. During 1982, the University also designed an integrated extruder-reactor system. The system combines the advantages of the extruder/feeder system with a unique static mixer reactor. The reactor concept has special capabilities for handling the very concentrated, viscous biomass slurries.

During 1982, Pacific Northwest Laboratory completed detailed analysis work centered on the oils produced at the Albany, Oregon, Biomass Direct Liquefaction Facility. The analysis included extensive characterization of the properties of the oil plus identification of major chemical constituents by gas chromatography/mass spectrometry. The most significant finding of this research is that the liquefaction oil is different from and superior to conventional pyrolysis oils. The liquefaction oil from both the PERC and LBL process concepts has lower oxygen content, is iess corrosive, and has significant quantities of phenolic constituents which may provide simple pathways for product upgrading. The liquefaction oils burn in test boilers with similar efficiencies to petroleum fuels, and Ames tests of both the LBL and PERC crude oils show no signs of product mutagenicity. Summary information on liquefaction product characterization is shown in Tables 1 and 2. During 1982, a final report on the multi-year research activities at the Albany, Oregon, Biomass Liquefaction Facility was completed by Wheelabrator Cleanfuel Corporation. The Facility was built in 1976 to test the feasibility of biomass direct liquefaction on a continuous basis and is shown in Figure 19. The report describes operation of the facility beginning in 1978 through completion in 1981 and provides a detailed summary of the research conducted during this period. Since 
Table 1. Physical Characteristics of Biomass Direct Liquefaction 0ils Produced at Albany, Oregon. (Moisture-free basis)

\section{Water Slurry (LBL) process $0 i 1$ Slurry (PERC) Process Test Run $7 \quad$ Test Run 8 Test Run 12}

Elemental Analysis \%

$\begin{array}{crrr}\text { C } & 80.2 & 84.2 & 80.6 \\ \text { H } & 8.5 & 8.7 & 10.3 \\ \text { O } & 11.1 & 6.6 & 9.1 \\ \text { N } & 0.2 & 0.5 & 0 \\ \text { Heating vaiue (Btu/1b) } & 15800 & 16300 & 15300 \\ \text { H/C Ratio } & 1.26 & 1.23 & 1.52\end{array}$

Table 2. Chemical Components of Biomass Direct Liquefaction Products as Determined by Gas Chromatography/Mass Spectrometry.

$$
\begin{array}{ll}
C_{5}-C_{6} \text { alcohols } & \text { phenols } \\
\text { cycloperitanones } & \text { methylnapthols } \\
\text { cyclopentenones } & \text { guaiacols } \\
C_{7}-C_{9} \text { cyclic Keytones } & \begin{array}{r}
\text { high molecular weight } \\
\text { guaiacols and oxygenates }
\end{array} \\
\text { dihydroxybenzenes } & \\
C_{8} \text { alkylbenzenes } &
\end{array}
$$




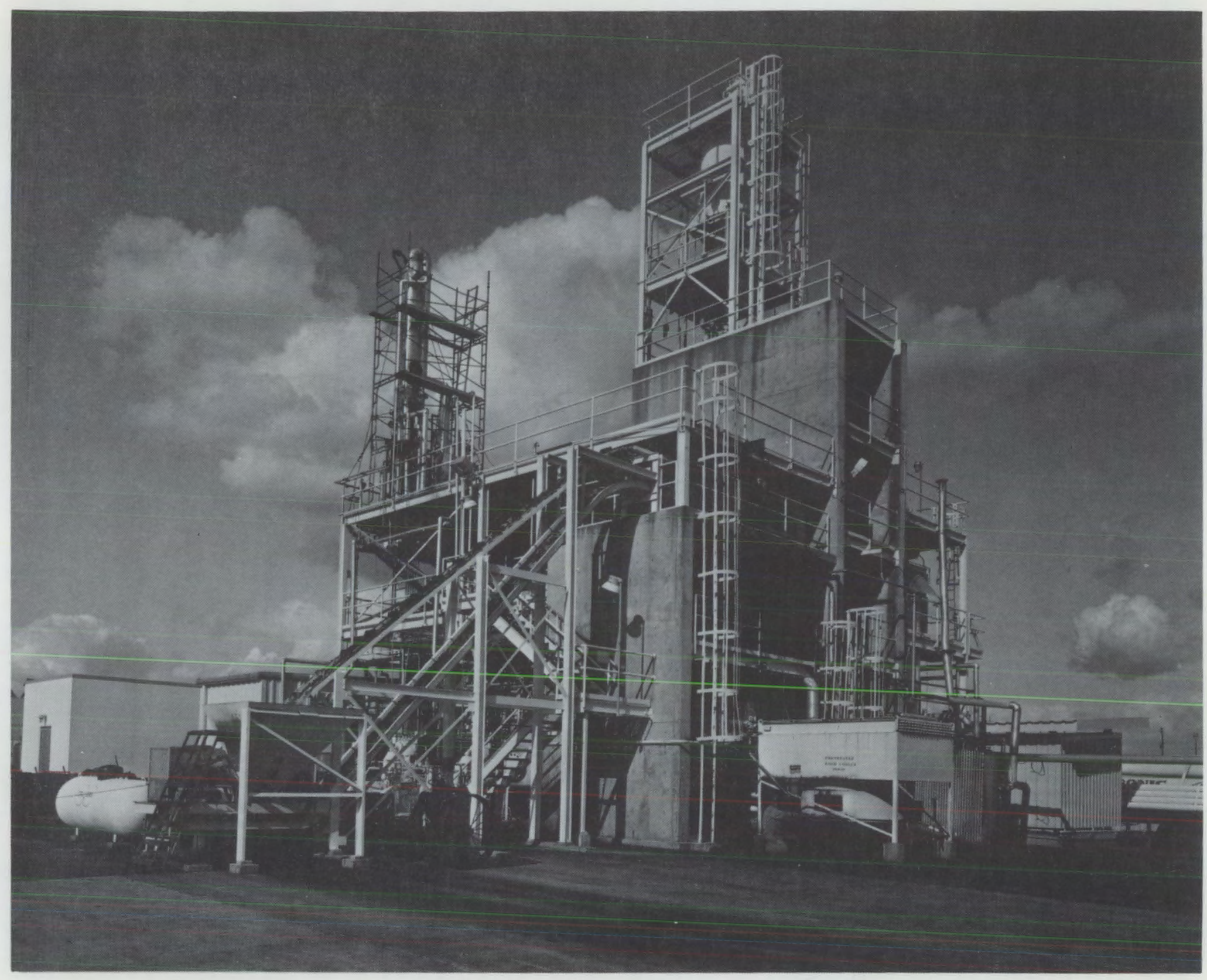

Figure 19. Biomass Liquefaction Facility, Albany, Dregon. Wood Feeder is Shown at Left. Pressurized Reactor Located Behind the Cement Shield. Fractional Distillation - Unit is Shown at Left on the Upper Deck. 

this facility was the first to produce multi-barrel quantities of biomass liquefaction oils, the final report serves as a reference volume for this benchmark effort. Major accomplishments include:

- First successful production of multi-barrel quantities of direct liquefaction oils on a continuous basis,

- Production of over 15,000 lbs of direct liquefaction oils for further testing and analysis,

- Verification of technical feasibility of the two major process alternatives with oil or aqueous transport siurries,

- Successful test firings of direct liquefaction oils in a smal1 boiler unit with combustion efficiencies equivalent to petroleum fuels,

- Production of an oil product superior to conventional pyrolys is oils due to lower oxygen content, higher heating value and other factors.

The research at Albany clearly showed the technical feasibility of producing biomass derived liquids by this type of process. Both the oil slurry (PERC) and aqueous slurry (LBL) process options were shown to be feasible in the continuous unit. In one test run alone during 1981, over 11,000 lbs of direct liquefaction oils were produced by operation in the oil slurry mode (PERC). The equipment configuration for this test run is shown in Figure 20 . The facility also made major contributions toward an understanding of the types of materials and reaction systems necessary for this type of work. The use of a high pressure, externally fired tubular reactor was shown to be feasible. The tubular reactor offers significant advantages in operational reliability and is easier to scale up than stirred tank reactors. Information on the types of valves, piping, and pumps necessary to handle both the feedstock slurries and the resulting products was also obtained. As indicated above, the product is substantially different from conventional pyrolysis oils and has many advantages over those products. 


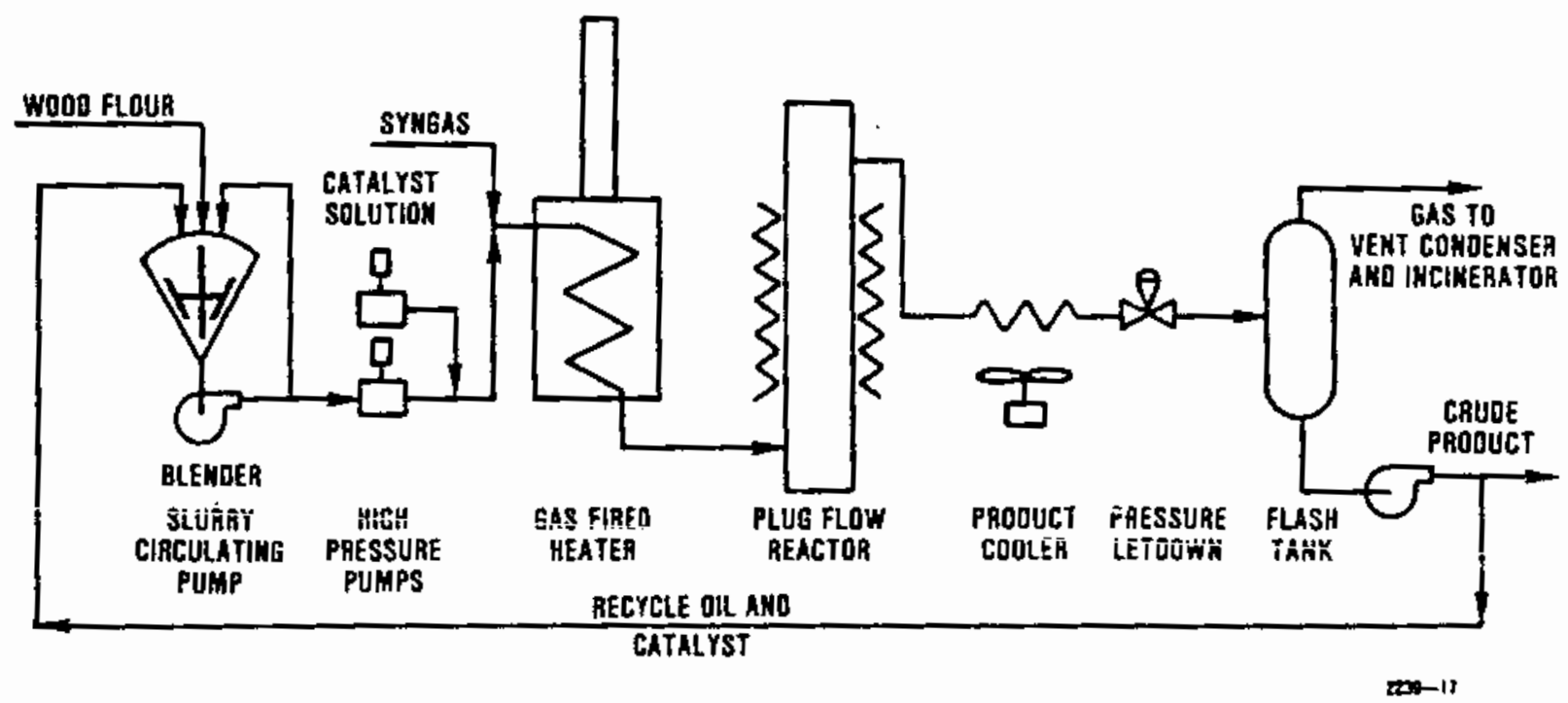

Figure 20. Equipment Configuration at Albany, Oregon, for 0i1 Slurry (PERC) Test Run Number Twelve 
Despite the demonstrated techrical feasibility, efforts to date at both Albany and at the bench scale have shown that the existing concepts are not currently economically feasible. The economic problems arise from large capital expenditures necessary for the complex facilities presently required and from process considerations such as large product oil recycle requirements. As a result, future research in direct liquefaction will be conducted on the fundamental level to generate the technical advances required before this conversion approach can be considered ready for engineering development. 


\section{DIRECT COMBUSTION TECHNOLOGY}

Direct combustion of biomass feedstocks, particularly wood, is already widely practiced by the private sector, especially in the forest products industry. Prior to the introduction of extensive natural gas distribution systems and cheap imported crude oil following world war II, many forest products companies utilized wood wastes from their operations to supply a portion of their energy needs. In the current era of expensive energy, there is wide spread interest in returning to self sufficiency in fuel supplies. Many types of direct combustion equipment, such as wood fired boilers and various types of burners, are commercially available for this purpose. Therefore, direct combustion projects funded by the Biomass Thermochemical Conversion Program have focused on unique, innovative combustion systems or special issues involved in utilizing biomass fuels.

The Biomass Thermochemical Conversion Program is currently sponsoring direct combustion research that is focused on determining the technical feasibility of converting the heat released from direct combustion directiy into mechanical power in small scale combustion engines. By directly producing mechanical power without the use of an intermediate working fluid, such as steam in a boiler-steam turbine system, high conversion efficiencies can be realized. In addition, costs associated with the working fluid, such as boilers and condensers are eliminated, allowing the small engines to operate economically. Research sponsored by the program is directed towards finding ways to efficiently replace petroleum fuels and natural gas in these small systems. As shown in Figure 21, the Biomass Thermochemical Conversion 


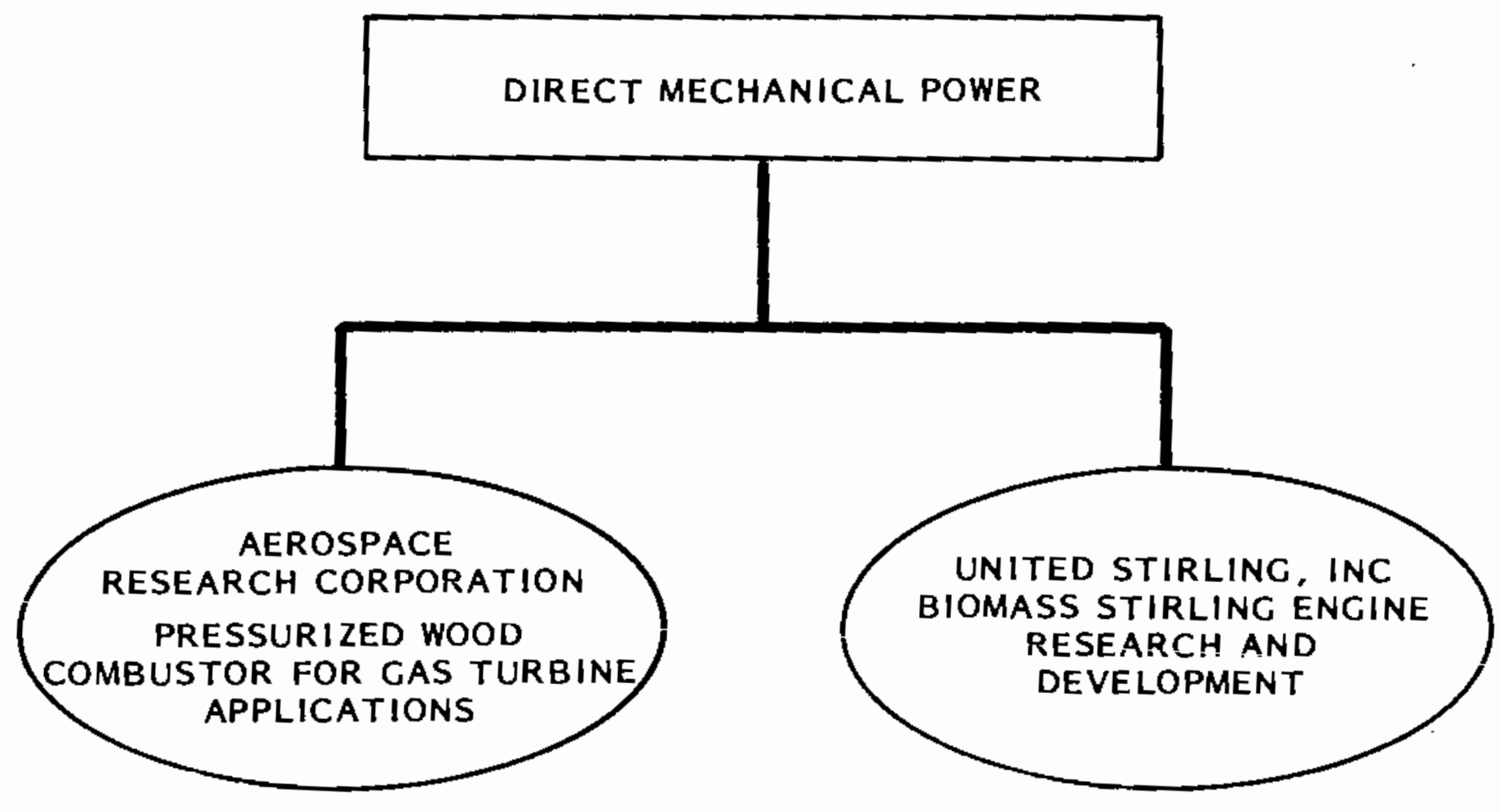

Figure 21. Direct Combustion Research Projects 
Program is currently sponsoring two research projects for using direct combustion of biomass in combustion engines.

United Stirling Inc., is conducting research on biomass fueled Stirling engines. The external combustion feature and high efficiency make the Stirling engine an attractive candidate for the direct production of shaft horsepower from solid fuels such as biomass. Other DOE programs have already committed extensive resources to the development of improved Stirling engines. The scope of this project is limited to the adaptation of Stirling engines to biomass fuels.

This project has been directed toward determining the technical feasibility of heating the Stirling engine heat exchanger, shown in Figure 22, with the hot flue gases from a small cyclonic combustor. Work to date has shown that wood ships as large as $3 / 8$ inch have suitable combustion characteristics in the cyclonic combustor and can be reasonably metered with a small screw feeder. Current research is focused on methods of ash removal from the combustor and on reduction of ash deposition on the heat exchanger.

Aerospace Research Corporation is conducting research on a directly fired gas turbine system using wood feedstocks. The objective of this project is to determine whether combustion gases from wood can be sufficiently cleaned using a series of cyclones to power gas turbines dependably and economically. Hot combustion gases from a pressurized wood-fired suspension burner are passed through a series of cyciones to remove particulate matter and are injected directly into a gas turbine. Tests using the $300 \mathrm{Kw}$ combustion turbine system shown in Figure 23 are being conducted to determine the amount of erosion and corrosion to the turbine buckets and stators, and the effects of wood type, moisture 


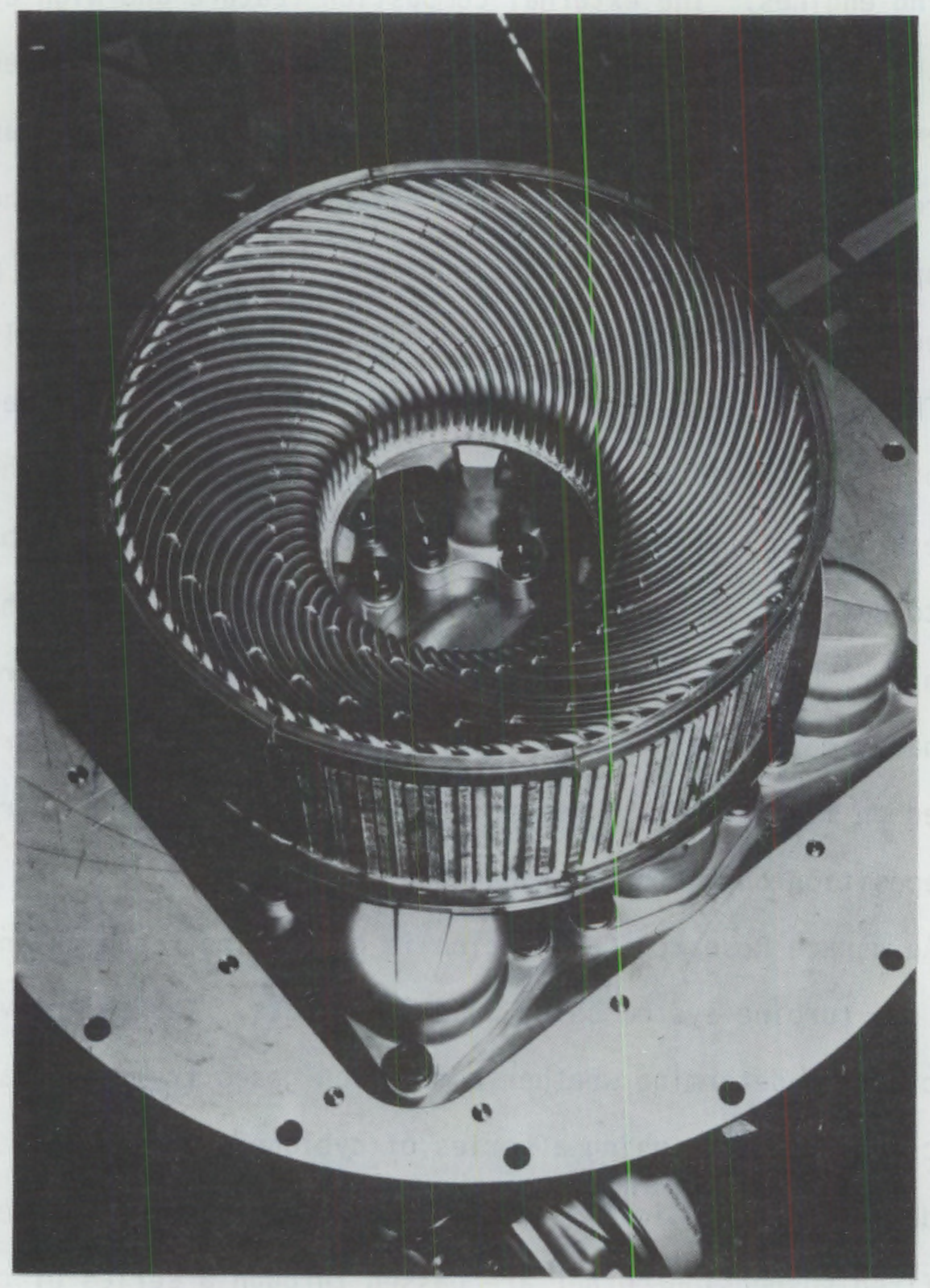

Figure 22. Involute Heat Exchanger on 4-95 Stirling Engine 


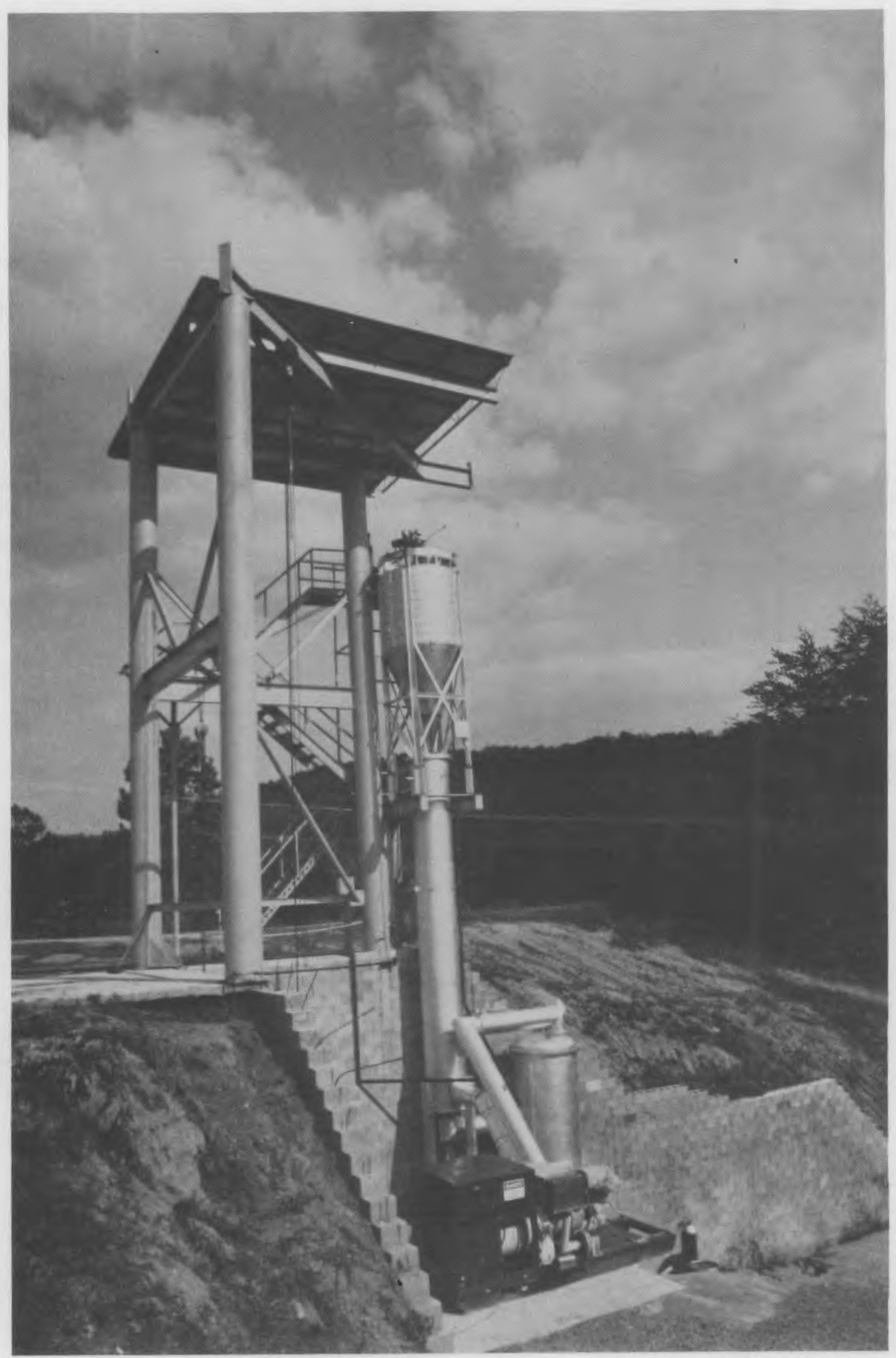

Figure 23. Wood Combustor/Gas Turbine-Generator System at Aerospace Research Corporation 


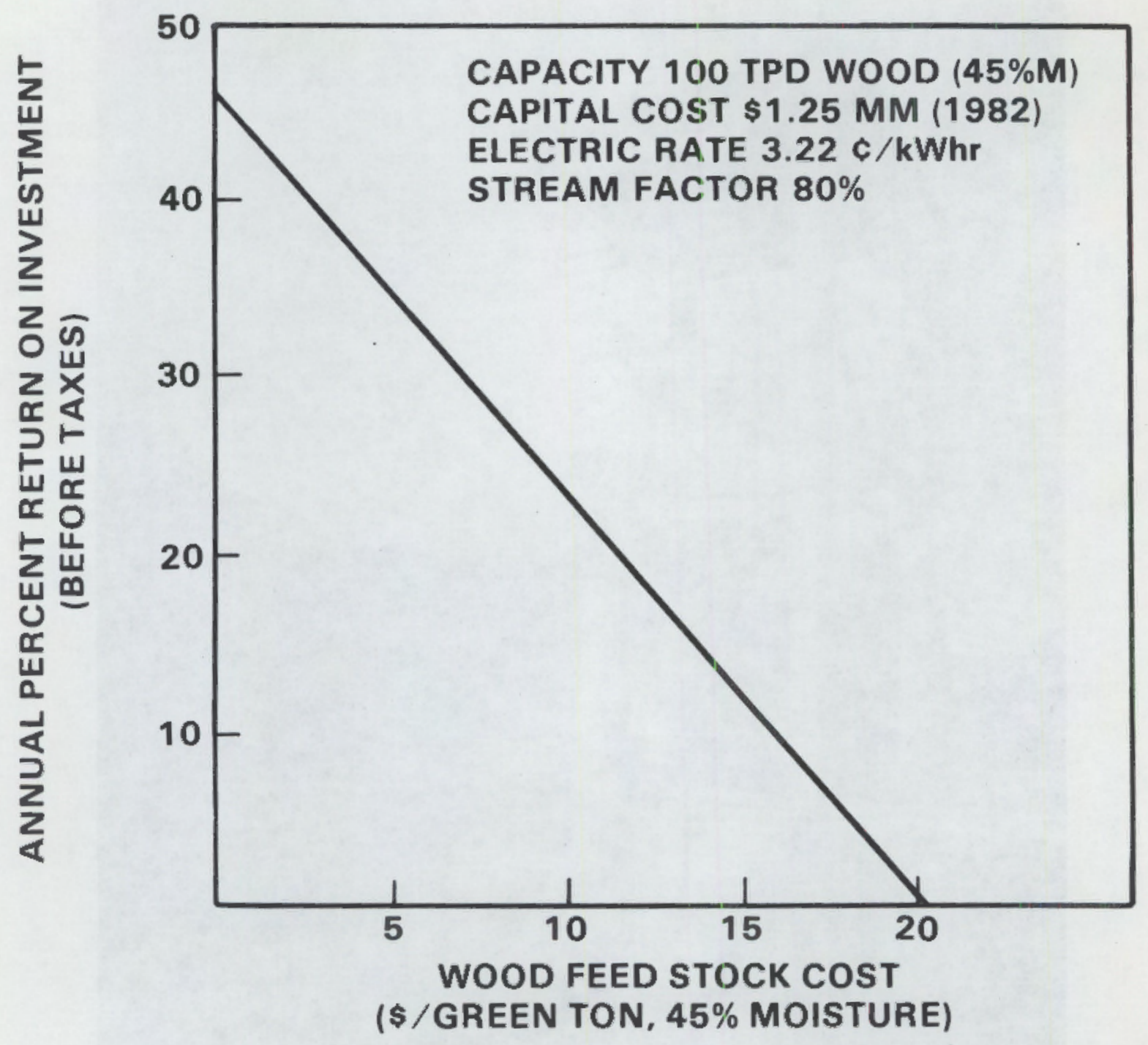

Figure 24. Return on Investment For a 3 MW Wood Combustor/Gas Turbine Generator System 
content, and particle size on system performance. Disassembly and examination of the turbine components following 200 hours of operation showed no significant signs of corrosion and only a soft, water soluble deposit which was easily removed. A total of 1,000 nours of testing is planned before final examination of the turbine components. Tests were also conducted to determine the mass concentration and particle size distribution of the wood combustion particulates entering the gas turbine. Data collected using an Anderson impactor showed that 80 to 90 percent of the particle mass was less than $0.5 \mathrm{~m}$ in diameter. The particulate loading entering the turbine ranged from 0.038 to 0.056 grains per dry standard cubic foot. These results and the results of the 200 hour test suggest that turbine erosion may be less of a problem than originally anticipated.

Projected economics for a complete three megawatt generating system are shown in figure 24. 


\section{PROGRAM SUPPORT ACTIVITIES}

During 1982, the Thermochemical Conversion Program sponsored additional research activities with the goal of supporting major program elements. This research includes evaluation of technoeconomic factors, evaluation of feedstock availability, arid cataloging of major research activities in biomass conversion. Program support research projects are described below.

Science Applications, Inc., (SAI) has conducted an engineering arid economic study to assess the applicability of five advanced biomass gasification concepts for the production of methanol. Alternative biomass-to-methanol flowsheets were developed for a conceptual 500 TPD grass roots methanol plant. The flowsheets were based on preliminary experimental data from small scale process research units at Pacific Northwest Laboratory, Wright-Malta Corporation, Texas Tech University, Battelle Columbus Laboratory and SERI. Capital and operating costs were estimated for twenty possible process configurations based on the five gasification concepts. Production costs were estimated for both private and utility financing. The results of this study showed that for a wood feedstock cost of $\$ 34 /$ dry ton, methanal production costs ranged from $\$ 0.70$ to $\$ 1.14$ per gallon using utility financing and from $\$ 0.85$ to $\$ 1.37$ per galion using private financing. Average production costs for the twenty alternative configurations were $\$ 0.83$ and $\$ 1.02$ per galion for utility and private financing, respectively. This price range is comparable to a gasoline cost between $\$ 1.22 /$ gal and $\$ 1.46 / g a 1$ on an energy equivalent basis when a $20 \%$ increase in engine efficiency from burning methanol, instead of gasoline, is taken into account. These 
results suggest that further research is warranted for developing advanced gasification processes for producing methanol synthesis gas.

Pyros Inc., is conducting research to determine the potential for supplying wood feedstocks to intermediate size (500-2000 tons/day of wood) conversion facilities in the Northeastern and Southeastern United States. This study is based in part upon the experience gained by the Burlington Electric Oepartment in setting up a wood supply infrastructure for a $50 \mathrm{MW}$ electric power plant in Vermont. This information is being used to estimate the potential for developing wood supply infrastructures in each region based on resource availability. The study will ultimately determine the potential for siting intermediate sized wood conversion facilities in both the Northeastern and Southeastern Unjted States.

SRI International completed a final report on the technoeconomic evaluation of biomass utitization processes. The goals of the "Solar Cost Data Bank" study was to develop projected economic costs for biomass feedstock/conversion technology options, to develop cost competitive goals for biomass technologies, and to identify options for achieving these cost goals. The final report presents technoeconomic evaluations for 25 biomass conversion processes ranging from gasification to ethanol production.

SRI concluded that biomass combustion offered the greatest potential near-term impact on U.S. energy supplies. SRI also identified and commented on several impediments to the development of biomass utilization including: 1) uncertain future frices of natural gas, 2) difficult access to biomass feedstocks on federal lands, 3) 
. 
potentially adverse environmental impacts of biomass production on miarginal lands, and 4) the safe disposal of bioconversion process wastes.

EnergyTrack, Inc., has been compiling a catalog of biomass thermochemical conversion projects. The goal of this work is to identify biomass conversion efforts on the national, regional, state, and locar levels. The catalog will be used in FY-83 as a planning document both to identify sources of technical expertise and to avoid unnecessary duplication of effort within the Thermochenical Conversion Program. 
APPENDIX A 


\section{BIBL IOGRAPHY}

Biomass Thermochemical Conversion Program

Publications for 1982 
Project Title: Biomass Thermochemical Conversion Program Management Lead Laboratory - Pacific Northwest Laboratory

1. "Proceedings of the 14 th Bionass Thermochenical Conversion Contractor's Meeting," Arlington, VA, June 23-24, 1982. (In press: to be published by NTIS).

2. Schiefelbein, G. F., D. J. Stevens, and M. A. Gerber. "Thermochemical Conversion of Biomass: A Summary of Research and Development Activities Sponsored by the Biomass Energy Technology Division, U.S. DOE," Presented at the Washington Society of Professional Engineers' Fifth Annual Energy Seminar, Seattle, WA, May 20-21, 1982.

3. Gerber, M. A., D. J. Stevens, and G. F. Schiefelbein. "Energy from Biomass; Thermochemical Prucesses," Presented at Energy Day in the Legislature (Washington State Legislature), Olympia, WA, February 19, 1982.

4. Stevens, D. J., G. F. Schiefelbein, and M. A. Gerber. "Biomass Direct Liquefaction Activities Sponsored by the U.S. Department of Energy, "Presented at the Specialists Heeting on Biomass Liquefaction, Saskatoon, Sasketchewan, Canada, February 16-18, 1982.

5. Schiefelbein, G. F., et al. "Thermochemical Conversion of Biomass: A Summary of R\&D Activities Sponsored by the Biomass Energy Technology Division of DOE," Pacific Northwest Laboratory, Richland, WA, December 1981, PNL-SA-10094 (NT1S).

6. Schiefelbein, G. F. "Thermochemical Conversion of Biomass: An Overview of R\&D Activities Sponsored by the Biomass Energy Technology Division," Presented at the 1981 Fall Meeting, Forest Products Research Society, Northern California Section, Sacramento, CA, November 19-20, 1981.

7. "Proceedings of the 13th Biomass Thermochemical Conversion Contractor's Meeting," Arlington, VA, October 27-29, 1981, CONF-8110115 (NTIS). 
Project Title: Development of Biomass Gasification to Produce Substitute Fuels - Institute of Gas Technology

1. Babu, S. P., li. Onischak, and G. Koscwski. "Development of a Presurrized Fluidized Bed Biomass Gasifier to Produce Substitute Fuels," presented at Biomass to Methanol Specialists" Workshop, Durango, C0, March 3-5, 1982.

2. Kosowski, G. M. G. R. Rose, S. P. Nandi, S. P. Singh, M. Onischak, R. F. Zabransky, and S. P. Babu. "Development of Biomass Gasification to Produce Substitute Fuels." Proceedings of the 13th Biomass Thermochemical Conversion Contractor's Meeting, Arlington, VA, October 27-29, 1981. CONF-8110115 (NTIS).

3. Kosowski, G. M., G. R. Rose, S. P. Nandi, M. Onischak, R, F. Zabransky, and S. P. Babu. "Development of Biomass Gasification to Produce Substitute Fuels." Proceedings of the 14th Biomass Thermochemical Conversion Contractor's Meeting, Arlington, VA, June 23-24, 1982. (To be published by NTIS).

4. Nandi, S. P., "Gasification of Chars Obtained from Maple and Jack Pine Woods." To be preserited at the Conference on Fundamentals of Thermochemical Bionass Conversion, Estes Park, CO, October $18-22,1982$.

5. Rose, G. R. "Devolatilization of Maple Harwood." To be presented at the Conference on Fundamentals of Thermochemical Biomass Conversion, Estes Park, C0, October 18-22, 1982.

Project Title: Conversion of Forest Residues to a Methane-Rich Gas - Battelle Columbus Laboratories

1. Feldmann, H. F., M. A. Paisley, H. R. Appelbaum, and B. C. Kim. "Steam Gasification of Forest Residues in a High-Throughput Gasifier." American Society of Mechanical Engineers, EnergySources Technology Conference \& Exhibition, New Orleans, LA, March 7-10, 1982.

2. Paisley, M. A., H. F. Feldmann, H. R. Appelbaum, and B. C. Kim. "Gasification of Forest Residues in a High Throughput Gasifier." The International Congress on Technology and Technology Exchange, Pittsburgh, PA, May 3-6, 1982.

3. Feldmann, H. F., et al. "Gasifjcation of Forest Residues to Produce a Methane-Rich Gas." Proceedings of the 13 th Biomass Thermochemical Conversion Contractor's Meeting, Arlington, VA, October 27-29, 1981, CONF-8110115 (NTIS). 
4. Feldmann, H. F., M. A. Paisley, and H. F. Appeibaum.

"Gasification of Forest Residues in a High-Throughput Gasifier." Proceedings of the 14th Biomass Thermochemical Conversion Contractor's Meeting, Artington, VA, June 23-24, 1982 (to be published by NTIS).

Project Titie: Investigation of Gasification of Biomass in the Presence of Catalysts - Pacific Northwest Laboratory

1. Mudge, L. K., E. G. Baker, and D. H. Mitcheil. "Catalytic Generation of Metharol Synthesis Gas from Wood," PNL-SA-10172, presented at the Biomass-to-Methanol Specialists Workshop, Durango, C0, March 3-5, 1982.

2. Mitche11, D. H., et ai. "Steam Gasification of Biomass in the Presence of Catalysts," Proceedings of the 13th Biomass Thermochemical Conversion Contractor's Meeting, Arlington, VA, October 27-29, 1981. CONF-8110115 (NTIS).

3. Mudge, L. K., et a1. "Steam Gasification of Wood in the Presence of Catalysts," Proceedings of the 14 th Biomass Thermochemical Conversion Contractor's Meeting, Arlington, VA, June 23-24, 1982. (To be published by NTIS).

4. Haggin, J. "Methanol from Biomass Draws Cluser to Market," Chemical \& Engineering News, July 12, 1982, pp. 24-45.

Project Title: Application of SGFM TEchnology to ATternate Feedstocks - Phase III - Texas Tech University

1. Beck, S. R., et a1. "Application of SGFM Technology to Alternate Feedstocks - Phase III." Proceedings of the 13th Biomass Thermochemical Conversion Contractor's Meeting, Arlington, VA, October 27-29, 1981 , CONF-8110115 (NTIS).

2. Beck, S. R., et al. "Application of SGF" Technology to Alternate Feedstocks - Phase III." Proceedings of the 14 th Biomass Thermochemical Conversion Contractor's Meeting, Arlington, VA, June 23-24, 1982 (to be pubtished by NTIS).

Project Title: Development of an Indirectly Heated Biomass Pyrolys is Reactor - Texas Tech University

1. Clements, D. L., et a1. "Development of an Indirectly Heated Biomass Pyrolysis Reactor." Proceedings of the 13th Biomass Thermochemical Conversion Contractor's Meeting, Arlington, VA, october 27-29, 1981, CONF-8110115 (NTIS). 
2. Clements, D. L. et al. "Development of an Indirectly Heated Biomass PryolysisReactor." Proceedings of the 14th Biomass Thermochemical Conversion Contractor's Meeting, Arlington, VA, June 23-24, 1982 (to be published by NIIS).

Project Title: Thermochemical Conversion of Biomass to Synthetic Fuels in a Large Experimenta? Facility (Phase II Recycling) - University of Missouri-Rolla

1. Flanigan, V.J., M. Findley, and S. Sineath. "Thermochemical Conversion of Biomass Synthetic Fuels in a Large Experimental Facility (Phase I) (to be published by NTIS).

2. Flanigan, V. J., M. Findley, and S. Sineath. "Thermochemical Conversion of Biomass to Synthetic Fuels in a Large Experimental Facility (Phase II-Recycling) (to be published by NTIS).

3. Flanigan, V. J., et a1. "Phase II Grow Project." Proceedings of the 13th Biomass Thermochemical Conversion Contractor's Nleeting, Arlington, VA, October 27-29, 19B1, CONF-8110115 (NTIS).

Project Title: Steam Gasification of Biomass-Wright Malta

1. Coffman, J. A. "Steam Gasification of Biomass." Proceedings of the 13thBiomass Thermochemical Conversion Contractor's Meeting, Arlington, VA,0ctober 27-29, 1981, CONF-8110115 (NTIS).

2. Coffman, J.A. "Steam Gasification of Biomass." Proceedings of the 14th Biomass Thermochemical Conversion Contractor's Meeting, Arlington, VA, June 23-24. 1982 (to be published by NTIS).

Project Title: The Simplex Process for the Gasification of Coal and Forest Pulp, Phase II - Dynecology, Iric.

1. Irwin, C. F. and R. B. Schulz. "Eriergy From Biomass: The Simplex Process for the Gasification of Coal and Forest Pulp." Proceedings of the 13th Biomass Thermochemical Conversion Contractor's Meeting, Arlington, VA, October 27-29, 1981, CONF-8110115 (NTIS). 
Project Title: Enträined-Flow, Ablative Fast Pyrolysis of Biomass Solar Energy Research Institute

1. Diebold, J. and J. Scahill. "Ablative Fast Pyrolysis of Biomass in the Entrained-Flow Cyclonic Reactor at SERI." Proceedings of the 14th Biomass Thermochemical Contractor's Review Meeting, Arlington, VA, 22-24 June 1982.

2. Diebald, J. and J. Scahi11. "Octcber 1981 Update on the Progress in the Entrained Flow, Fast Pyrolysis of Biomass." Proceedings of the 13th Biomass Thermochemical Contractor's Meeting, Arlington, VA, 27-29 0ctober 1981 (NTIS) CONF-8110115.

Project Title: Flash Pyrolysis and Hydropyrolysis of Biomass Brookhaven Nationat Laboratory

1. Steinberg, M. and P. T. Fallon. "Flash Pyrolysis of Biomass with Reactive and Non-reactive Gases." Proceedings of the 14th Biomass Thernochemical Conversion Contractor's Meeting, Arlington, VA, June $23-24,1982$ (to be published by NTIS).

2. Steinberg, M. and P. T. Fallon. "Flâsh Pyrolysis and Hydropyrolys is of Biomass." BNL 31271 , to be presented at the 17 th IECEC meeting in Los Angeles, CA (August 8-13, 1982).

3. Steinberg M. and P. T. Fallon. "Flash Pyrolysis and Hydropyrolysis of Biomass." Proceedings of the 13th Biomass Thermochemical Conversion Contractor's Meeting, Arlington, VA, october 27-29, 1981, CONF-8110115 (NTIS).

Project Title: Research on the Pyrolysis of Hardwood in an Entrained Bed Process Research Unit - Georgia Tech University

1. Knight, J. A., C. W. Gorton, R. J. Kovac, L. W. Elston, and D. R. Hurst. "0i\} Production via Entrained Flow Pyrolysis of Biomass", Proceedings of the 13th Thermochemical Conversion Contractor's Meeting, Arlington, VA, October 27-29, 1981. CONF-8110115 (NTIS).

2. Knight, J. A., C. W. Gorton, R. J. Kovac, L. W. Elston, D. R. Hurst, and J. H. Murphy. "Thermochemical Conversion of Biomass to Syngas via the Georgia Tech Entrained Pyrolysis/Gasification Process", Final Report, Apri1, 1982. (To be published by NTIS).

3. Knight, J. A., C. W. Gorton, R. J. Kovac, and L. W. Elston. "Entrained Flow Pyrolysis of Biomass", Proceedings of the 14th Biomass Thermochemical Conversion Contractor's Meeting, Arlington, VA, June $23-24,1982$. (To be published by NTIS). 
4. Knight, J. A., and C.W. Gorton. "Entrained Flow Pyrolysis of Biomass", Biomass Research Conference, TVA, July 12-13, 1982, Muscle Shoals, AL.

Project Title: Fundamental Pyrolysis Studies - Solar Energy Research Instjtute

1. Milne, T. A., and M. N. Soltys. "Fundamental Pyrolysis Studies. Annual Report for Fiscal Year 1981." Proceedings of the 13th Biomass Thermochemical Conversion Contractor's Meeting, Arlington, VA, October 27-29, 1981, CONF-8110115 (NTIS).

2. Milne, T. A. and M. N. Soltys. 1982. Fundamental Pyrolysis Studies. Quarterly Report, October-December 1981. SERI/PR-234-1537. Golden, CO: Solar Energy Research Instjtute.

3. Milne, T. A., and M. N. Soltys, 1982, "The Direct Observation of Pyrolysis Behavior of Carbonaceous Solids in a Hot-Steam Argon Environment." Paper presented at the Spring Meeting of the Western States Section of the Combustion Institute, April 5-6, 1982. Salt Lake City. SERI/TP-234-1524. Golden, C0: Solar Energy Research Institute.

4. Milne, T. A., and M. N. Soltys. 1982. Fundamental Pyrolys is Studies, Quarterly Report, January-March 1982.

SERI/PR-234-1617. Golden, C0: Solar Energy Research Institute.

5. Milne, T. A., and M. N. Soltys. 1982. "Fundamental Pyrolysis Studies." Presented at the 14th Biomass Thermochemical Conversion Contractor's Meeting, Arlington, VA, June 23-24, 1982. (To be published by NTIS).

6. Seibert, J., G. Folger, and T. Milne. 1982. "Alcohol CoProduction from Tree crops." Presented at the Meeting of the American Section of the International Solar Energy Society. June $1-3,1982$, Houston, TX.

Project: Detailed Studies of the Effects of Pressure on Biomass Gasification - University of Hawaji

1. Antal, M. J. and W. S. Mok. "Effects of Pressure on Biomass Pyrolysis and Gasification." Proceedings of the 13th Biomass Thermochemical Conversion Contractor's Meeting, Arlington, VA. October 27-29, 1981, CONF-8110115 (NTIS).

2. Anta], M. J. "Effects of Pressure on Biomass Pyrotysis." Proceedings of the 14th Biomass Thermochemical Conversion Contractor's Meeting, Arlington, VA, June 23-24, 1982 (to be publ ished by NTIS). 
Project Title: Gas Turbine Demonstration of Pyrolysis-Derived Fuels Teledyne CAE

1. Jasas, G., and J. Kasper. "Gas Turbine Demonstration of Pyrolysis Derived Fuels," Proceedings of the 14 th Biomass Thermochemical Conversion Contractor's Meeting, Arlington, VA, June $23-24,1982$. (To be published by NTIS). 
Project Title: Examination of Alternative Catalysts For Direct Liquefaction - SRI International

1. Rogers, D. Z. and T. D. An. "Examination of Alternative Catalysts For Direct Biomass Liquefaction." Proceedings of the 13th Biomass Thermochemical Conversion Contractor's Meeting, Arlington, VA, October 27-29, 1981, CONF-8110115 (NTIS).

2. Rogers, D. Z. and T. D. An. "Examination of Alternative Catalysts For Biomass Direct Liquefaction." Proceedings of the 14 th Biomass Thermochemical Conversion Contractor's Meeting, Arlington, VA, June 23-24, 1982 (to be published by NTIS).

3. Tran, A. D. and D. Z. Rogers. "Examination of A1ternative Catalysts for Biomass Direct Liquefaction." Final Report. be pubTished by NTIS).

Project Title: Modified Extruder for Feeding Find-Ground Celiulosic Slurries to Pressure Systems - University of Arizona

1. White, D. H., et a1. "Modified Extruder for Feeding Fine-Ground Cellulosic Slurries to Pressure Systems", Proceedings of the 13th Biomass Thermochemical Conversion Contractor's Meeting, Arlington, VA, October 27-29, 1981, CONF-8110115 (NTIS).

Project Title: Research and Oevelopment Activities on Direct Liquefaction Technology - Lawrence Berkeley Laboratory

1. "Catalytic Liquefaction of Biomass." Proceedings of the 13th Biomass Thermochemical Conversion Contractor's Meeting, Arlington, VA, October 27-29, 1981, CONF-8110115 (NTIS).

2. Davis, H., K. Kloden, L. Schaleger, and N. Yaghoubzadeh. Research and Development Activities on Direct Liquefaction Technology Quarterly Report. July-September 1981. LBID-458.

3. Figueroa, C., L. Schajeger, and $H$. Davis. LBL Continuous Bench-Scale Liquefaction Unit, Operation and Results. Presented at the 6th Annual Conference on Energy from Biomass and Wastes, January 25-29, 1982. LBL-13709.

4. Davis, H., et al. Research and Development Activities on Direct Liquefaction Technology Quarterly Report. October-December 1981. LBID -470 .

5. Davis, H. G. Hydrogen or Carbon Monoxide in the Liquefaction of Biomass. Presented at the World Hydrogen Energy Conference IV, June 13-17, 1982, Pasadena, CA. LBL-14D18. 
6. Schaleger, L. L. and H. G. Davis. Progress in the Characterization of the Products of Direct Liquefaction of Douglas Fir. workshop/Review Meeting on biomass 1 iquefaction research, National Research Council of Canada, Saskatoon, February 16 and 17, 1982. LBL-14017.

7. David, H. G. Direct Liquefaction of Biomass Biomass: Results from Operation of Continuous Bench Scale Unit in Liquefaction of Water Slurries of Douglas Fir Wood. Presented at the 4 th Symposium on Biotechnology in Energy Production and Conservation, May 11-14, 1982, Gatlinburg, Tenn. LBL-14019.

8. Davis, H. G., G. Figueroa, and L. L. Schaleger. Research and Development Activities on Direct Liquefaction Technology Quarterly Report. January-March 1982. LBID-539.

9. Davis, H. G., et al. Research and Development Activities on Direct Liquefaction Technology, Presented at the 14th Biomass Thermal Chemical Conversion Contractor's Meeting, Arlington, VA, June 23-24, 1982. (To be published by NTIS.)

10. Yu, S. M. Solvolytic Liquefaction of Wood Under Mild Conditions. Ph.D. Thesis, Apri] 1982. LBL-14096.

Project Title: Research at the Albany, Oregon, Biomass Liquefaction Facility - Wheelabrator Cleanfuel Corporation

1. Rust International Corporacion, "Final Report: An Investigation of Liquefaction of Wood." April, 1982. (To be pubiished by NTIS.) 


\section{DIRECT COMBUSTION TECHNOLOGY}

Project Title: Biomass Fueled Stirling Engine System Research United Stirling, Inc.

1. Percival, W. H., and B. Hansson. "Bjomass Fueled Stirling Engine System Research and Development," Proceedings of the 14th Biomass Thermochemical Conversion Contractor's Meeting, Arlington, VA, June 23-24, 1982 (to be published by NTIS).

2. Guntresson, S., and B. Hansson. "Biomass Fueled Stirling Engine Research and Development," Proceedings of the 13 th Biomass Thernochemical Conversion Contractor's Meeting, Arlingtor, VA, October 27-29, 1981, CONF-B110115 (NTIS).

Project Title: Development of Wood as an Alternative Fuel for Large Power Generating System - Aerospace Research Corporation

1. Hamrick, J. T. "Development of Wood as an Alternative Fuel for Gas Turbine Systems." Proceedings of the 13th Thermochemical Conversion Contractor's Meeting, Arlingtor, VA, October 27-29, 1981, CONF-8110115 (NTIS).

2. Hamrick, J. T. "Development of Wood as an Alternative Fuel for Gas Turbine Systems." Proceedings of the $14 \mathrm{th}$ Thermochemical Conversion Contractor's Meeting, Arlington, VA, June 23-24, 1982 (to be published by NTIS). 
Project Title: Biomass Based Methanol Processes - Science Applications, inc.

1. Wan, E. I., et al. "Technical and Economic Assessment of Liquid-Fuel Production from Biomass," Proceedings of the 13th Biomass Thermochemical Conversion Contractor's Meeting, Arlington, VA, October $27-29,1981$, CONF-8110115 (NTIS).

2. Wan, E. I., et al. "Economic Evaluation of Indirect Biomass Liquefaction Processes for Production of Methanol and Gasoline," paper presented at IGT's Sixth Annual Meeting on Energy from Biomass and Wastes, Buena Vista, FL, February 1982.

3. Wan, E. I., and J. D. Price. "Technical and Economic Assessment of Liquid-Fuel Production from Biomass," Proceedings of the 14th Biomass Thermochemical Conversion Contractor's Meeting, Arlington, VA, June 23-24, 1982. (To be published by NTIS).

Project Title: Preparation of a Solar Cost Data Bank for the DOE Fuels from Biomass Systems Branch - SRI International

1. Kinderman, E. M., P. Meagher, D. L. Olsen, W. J. Short, J. W. Stallings, N. Teater, and D. J. Wilhelm. "Technical and Economic Evaluations of Biomass Utilization Processes: Solar cost Data Bank - Final Report." July, 1982. (To be published by NTIS.) 


\section{DISTRIBUTION LIST}

No. of

Copies

OFFSITE

10 Simon Friedrich

Biomass Energy Technology Division

U.S. Department of Energy

Forrestal Building (CE-321)

1000 Independence Avenu

Washington, D.C. 20585

Beverly Berger, Director

Biomass Energy Technology Division

U.S. Department of Energy

Forrestal Building (CE-321)

1000 Independence Avenue

Washington, D.C. 20585

Jerome F. Collins, Chief

Alternative Materials Util. Br. Office of Industrial Programs

U.S. Department of Energy

1000 Independence Avenue, SW

Washington, D.C. 20585

Sig Gronich

Office of Alcohol Fuels

U.S. Department of Energy

Forrestal Building, (CE-80)

Washington, D.C. 20585

Donald K. Walter

Office of Energy from

Municipal Waste

CE-323 Forrestal Building

U.S. Department of Energy

1000 Independence Avenue, SW

Washington, D.C. 20585

27 DOE Technical Information

Center

Mr. John Allen

Battelle

Columbus Laboratories

$505 \mathrm{King}$ Avenue

Columbus, $\mathrm{OH} 43201$
No. of

Copies
Dr. Michael J. Antal, Jr.

Coral Professor

Dept. of Mechanical

Engineering

University of Hawai

2540 Dole Street

Honolulu, HI 96822

Mr. Suresh Babu

Institute of Gas Technology

IIT Center

3424 South State Street

Chicago, IL 60616

Mr. W. G. Bair

Assistant Vice President

Process Research

Institute of Gas Technology

3424 South State Street

Chicago, IL

Mr. Andrew J. Baker

Chemistry \& Paper Research

U.S. Forest Products Lab

P.0. Box 5130

Madisor, WI 53705

Dr. Steven R. Beck

Department of Chem. Eng.

Texas Tech University

P.L. Box 4679

Lubbock, TX 79409

Mr. Paul F. Bente, Jr.

The Bio-Energy Council 825A

1625 Eye St., NW

Washington, D.C. 20006

Mr. Walter L. Berry, Jr.

Rust Engineering Company

P.0. Box 101

Birmingham, $A L$ 352D1 
No. of

Copies

Mr. Eric F. Brandt

Vice President, Operations

Banyan Technology Corporation

7515 Greenville Avenue, Suite 711

Dallas, TX 75231

Mr. Phillip Bridges

Conrad Industries

606 Reynolds Avenue

Centralia, WA 98531

Mr. William S. Bulpitt, Chief

Wood Energy Systems Division

Engineering Experiment Station

Georgia Institute of Technology

Room 223, 0'Keefe Bldg.

Atlanta, GA 30332

Dr. James L. Butler, Manager

SEA Southen Agri. Energy Center

Coastal Plain Experiment Station

Tifton, GA 31793

Ms. Karen Chopp, Manager

Resource Recovery

Kimberly-Clark Corporation

Neenah, WI 54956

Mr. Dave Christensen, Manager

Alternate Energy Programs

Scientific Serv. \& Systems Grp.

Wyle Laboratories

7800 Governors Drive West

Huntsville, AL 35807

Dr. David F. Ciliberti

Fellow Engineer

Westinghouse Electric Corp.

1310 BeuTah Road

Pittsburgh, PA 15235

Dr. L. Davis Clements

Dept. of Chemical Engineering

Texas Tech University

P. 0. Box 4679

Lubbock, TX 79409
No. of

Copies

Mr. John A. Coffman

Wright-Malta Corporation

Malta Test Station

Plains Road

Ballston Spa, NY 12020

Mr. James Cummings-Saxton

Project Manager

Argonne National Laboratory

9700 S. Cass Avenue

Argonne, IL 60439

Dr. Hubert G. Davis

Lawrence Berkeley Laboratory

University of California

91 Bolivar Drive

Berkeley, CA 94720

Dr. James $P$. Diebold

Solar Energy Research Institute

1617 Cole Boulevard

Golden, CO B0401

Prof. 0tto C. Doering, III

Director, Energy Policy Research and Information Program

Purdue University

West Lafayette, IN 47907

Mr. Richard L. Durham

Special Assistant to the Director

Oregon Department of Energy

Labor \& Industries Building

Room 102

Salem, OR 97301

Mr. F. J. Dyches, Manager

Energy Utilization

Camas Mit1

Crown Zellerbach

Camas, WA 98607

Mr. Charles Eumurian

Vice President

Engineering and Manufacturing

Enerdyne Corporation

7430 Washington Ave. South

Minneapolis, MN 55344 
No. of

Copies

Mr. Herman F. Feldman

Battelle

Columbus Laboratories

$505 \mathrm{King}$ Avenue

Columbus, $\mathrm{OH} 43201$

Dr. Virgil J. Flanigan

Gasification Research on Wood Univ. of Missouri - Rolla

Rolla, MO 65401

Mr. Patrick Fox

Biomass Program Manager

Bonneville Power Administration

Routing, EPG

U.S. Department of Energy

P.0. Box 3261

Portiand, OR 97208

$\mathrm{Mr}$. Roger Gaire

Business Development Manager

Foster Wheeler Synfuels Corp.

110 South Orange Ave.

Livingston, NJ 07039

Ms. Mary Wolter Glass

Fred C. Hart Associates, Inc.

1110 Vermont Ave. NW, Suite 410

Washington, DC 20005

Mr. C. W. Gorton

School of Chemical Engineering Georgia Institute of Technology

Atlanta, GA 30332

Dr. W. Scott Gray

Executive Engineer

Research and Engineering

Bechtel Group, Inc.

Fifty Beale Street

P.0. Box 3965

San Francisco, CA 94119

Mr. Troy R. Green, Director

Alternative Energy Development

Standard $0 i l$ of Indiana

AMOCO Research Center

Warrenvilie Road

P.0. Box 400

Naperville, IL 60540
No. of

Copies

Mr. Joseph T. Hamrick

Aerospace Research Corporation

5454 Jae Valley Road

Roanoke, VA 24014

$\mathrm{Mr}$. Howard Haines

Energy Division DNRC

Helena, MT 59601

Mr. James E. Helt

Chemical Engineer

Argonne National Laboratory

Building 205

9700 S. Cass Avenue

Argonne, IL 60439

Mr. R. Anthony Henrick

Central Plants, Inc.

6140 Bristol Parkway

P. 0. Box 3233

Culver City, CA 90230

Prof. Richard Hill

Dept. of Industrial Coop.

University of Maine

109 Boardman Hall

orono, ME 04473

Mr. Randy Hoskins

TransEnergy Systerns

14711 North Easy 29 th P1.

Bellevue, WA 98007

Mr. Aller Jaisle

DOE Planning and Development

State of Minnesota

2728 Chowen Avenue South

Minneapolis, MN 55416

Mr. Branyon 0. Jarrett, Jr.,

Wood Energy Engineer

Georgia Forestry Commission

7 Martin Luther King, Jr. Dr., SW

Atlanta, GA 30334

Mr. Charles A. Job

GRI

B600 West Bryn Mawr Avenue

Chicago, IL 60631 
No. of

Copies

Mr. Paul C. Juhasz

Washington State Energy Office

1st Floor, ER-11

$400 \mathrm{E}$. Union

OTympia, WA 98504

Mr. Richard Kaplan

Crawford \& Russell

P. 0. Box 1432

Stamford, CT 06904

Mr. Donald L. Klass

Institute of Gas Technology

IIT Center

3424 South State Street

Chicago, IL 60616

Dr. William H. Klausmeier

Energy \& Environ. Sys. Division

Argonne National Laboratory

9700 South Cass Avenue

Argonne, IL 60439

Mr. A. T. Knecht

Director

BioEngineering Center

ARCO Solar Industries

P.0. Box 2600

Dublin, CA 94566

Dr. James A. Knight

Eng. Experimental Station Area 2 Georgia Institute of Technology

Atlanta, GA 30332

Mr. Allen M. Koleff

Director of Technology

Stone Container Corp.

P. 0. Box 427

Franklin, $\mathrm{OH} 45005$

Mr. Herbert M. Kosstrin

Stone \& Webster Engineering Corp. 245 Surnmer Street

Boston, MA 02107

Mr. A. W. Kramer

Thermal Energy Systems

The Proctor and Gamble Co. 6105 Center Hill Road

Cincinnati, OH 45224
No. of

Copies

Mr. John Krochta

U.S. Dept. of Agriculture

800 Buchanan Street

Berkeley, CA 94710

Dr. James Kuester

Dept. of Chem. Engineering

Arizona State University

Tempe, AZ 85281

Mr. Harry La Fontaine

1995 Keystone BTvd.

Miami, FL 33181

Mr. Michael Lambert

USDA Forest Services

$809 \mathrm{NE} 6$ th Avenue

Portland, OR 97232

Mr. Larry Larson

Southern California Edison

P.0. Box 800

Rosemead, CA 91770

Dr. R. Eric Leber, Ph.D.

Director of Energy Research

American Pub1 ic Power Assoc.

2301 M Street, NW

Washington, D.C. 20037

Mr. Leslie S. Levine

JAYCOR

205 South Whiting St.

Alexandria, VA 22304

Mr. Dean B. Mahin

Internationa] Energy Proj.

Box 591

Front Roya1, VA 22630

3r. Thomas F. McGowan

wood Energy Systems Branch

Eng. Experimental Station

Georgia Institute of Tech.

At Tanta, GA 30332

Mr. Frank McManus

Resource Recovery Report

1707 H Street NW, Suite 607

Washington, D.C. 20006 
No. of

Copies

Mr. Thomas R. Miles

Consulting Design Engineers

5475 S.W. Arrowwood Lane

Portland, OR 97225

Dr. G. R. Miller

Black and Veatch

1500 Meadow Lake Parkway

P. 0. Box 8405

Kansas City, MO 64114

Dr. Thomas A. Milne

Solar Energy Research Inst.

1617 Cole Blvd.

Golden, C0 80401

Mr. Boyd Montgomery

National Synfuels, Inc.

P. 0. Box 209

Jacksonville, FL 32203

Ms. Ethely P. Mot ley

Assistant Manager, Engineering

Chemical Engieering Laboratory

TRW Energy Development Group

Building 01, Room 2251

One Space Park

Redondo Beach, CA 90278

Mr. Ping-Kuen (Eric) Mun

ARCO Solar Industries

BioEngineering Center

P.0. Box 260D

Dubl in, CA 94566

Mr. Richard A. Nissen

Senior Mechanical Engineer

520 North Michigan Avenue

0il Dri Corp. of America

Chicago, IL 60611

Mr. E. F. (Woodie) 0lver

U.S. Department of Agriculture

Energy Integrated Farms

Sys Prog (DOE)

14 th \& Independence

440-A Administration Building

Wastington, DC 20250
No. of

Copies

Mr. Michael Onischak

Institute of Gas Technology

IIT Center

3424 South State Street

Chicago, IL 60616

Mr. Forrest E. Orr

Pyros, Inc.

656 Quince Orchard Road, Suite 304

Gaithersburg, MD 20760

Mr. Mark Paisley

Battelle

Columbus Laboratories

505 King Avenue

Columbus, $\mathrm{OH} 43201$

Mr. Robert M. Peart

Agri. Engineering Department

Purdue University

W. Lafayette, IN 47907

Mr. Worth Percival

United Stirling, Inc.

211 The Strand

Alexandria, VA 22314

Mr. Archie H. Perugi

Manager, Engineering

Energy Appli. Prog. Dept.

General Electric Company

Schenectady, NY 12345

Dr. William A. Peters

Massachusetts Inst. of Tech. E40-419 (Energy Laboratory)

Cambridge, MA 02139

Mr. Tony Petricola

Archer Daniels Midland Co.

P.0. Box 1470

Decatur, IL 62525

Mr. Shaik A. Qader

Jet Propulsion Laboratory

California Inst. of Tech.

480D Oak Grove Drive

Pasadena, CA 91109 
No. of

Copies

$\mathrm{Mr}$. Zenon Redkevitch

Energy and Mtrls. Sci. Lab.

Eng. Experiment Station

Georgia Institute of Tech.

Atlanta, GA 30332

Mr. Joe Roetheli

Assist. Mgr., Biomass Fuels

Office of Agricultural and

Chemical Development

Tennessee Valley Authority

Muscle Shoals, AL 35660

$\mathrm{Mr}$. John Rohrer

Wheelabrator Frye, Inc.

Liberty Lane

Hampton, NH 03842

Mr. Seymour I. Rosenthal

Manager of Proposals

Foster wheeler Synfuels Corp.

110 South Orange Avenue

Livingston, No 07039

Mr. Milton D. Scheer

Chemical Kinetics Div. (542)

National Bureau of Standards

Washington, D.C. 20234

Mr. David R. Shields

Executive Vice President

National Synfuels, Inc.

P. 0. Box 40239

239 Chambliss Street

Jacksonville, FL

Dr. George M. Simmons

University of Idaho

Dept. of Chemical Engineering

Buchanan Eng. Laboratory 308

Moscow, ID 83843

Dr. W. H. Smith, Director

Center for Biomass Energy Systems

University of Florida

3038 McCarty Hall

Gainesville, FL 32611
No. of

Copies

Mr. John L. Stafford, P.E.

Process Consultant

Guaranty Fuels, Inc.

P. 0 . Box 748

Independence, KS 67301

Or. Meyer Steinberg

Brookhaven National Laboratory

Upton, Long Island, NY 11973

Mr. Peter A. Stranges

United Technologies Research Center

1125 15th Street, NW

Washington, D.C. 20005

Mr. K. Subramanian

International Harvester

Science and Technology Laboratory

16 W. 26083 rd St.

Hinsdale, IL 60521

Mr. Abu Talib

The Mitre Corporation/Metrek Division

1820 Dolley Madison Blvd.

McLean, VA 22102

Mr. Gary Underhil1

Camas Associates

P.0. Box 1163

Roseburg, OR 97470

Mr. Charles W. Vait

BIOSYS Corporation

254 North Washington Street

=alls CHurch, VA 22046

Mr. Robert Van Hook, Manager Woody Biomass Production Program Environmental Sciences Division Oak Ridge Nationa! Laboratory Bldg. 1505

P.0. Box X

(lak Ridge, TN 37830

Mr. Robert H. Vander Molen

Combustion Power Company

1346 Willow Road

Menlo Park, CA 94025 
No. of

Copies

$\mathrm{Mr}$. James L. Walsh, Jr., PE Energy Systems Group Georgia Institute of Tech. Eng. Experiment Station

Atlanta, GA 30332

Dr. Edward I. Wan

Science Applications, Inc.

1710 Goodridge Drive

McLean, VA 22102

Mr. Tse-Wei Wang

Assist. Director, Bioenergy

Energy, Environment and Resources Center

The University of Tennessee

327 South Stadium Hall

Knoxville, TN 37916

Dr. Don H. White

University of Arizona

College of Mines

Tucson, AZ 85721

Mr. R. L. Wilkins

Proctor \& Gamble Company

7162 Reading Road

Cincinnati, $\mathrm{OH} 45222$

Ms. Joan Wood

Tennessee Valley Authority

320 Credit Union Bldg.

Chattanooga, TN 37401

\section{FOREIGN}

Mr. Tony Bridgwater

The University of Aston in

Birmingham

Dept. of Chemical Engineering

Gosta Green

Birmingham, ENGLAND B4 7ET

Dott. Guido Cogliati

AGIP Nucleare

ROME

3272661
No. of

Copies

Mr. T. Cotton, P.E.

B. H. Levelton \& Associates Ltd 8805 0sler Street

Vancouver, B.C., CANADA V6P $4 \mathrm{Gl}$

Mr. D. J. Orovet

$37 \mathrm{c} 3$, Avenue Franklin Roosevelt 75008 Paris - FRANCE

Prof. M. Gelus

Creusot-Loire - Division Energie BP 31 Cedex

71208 Le Creusot, FRANCE

Emilio M. A. Gomez

Agricultural Engineer

Empresa Nacionai Adaro

De Investigaciones Mineras, S.A.

Serrans, 116

Madrid - 6, SPAIN

R. G. Graham

The University of Western Ontario Faculty of Engineering Science London, CANADA NGA 5B9

Prof. P. D. Grover

Indian Institute of Technology, Delhi

Chemical Engineering Dept.

New Delhi, INDIA 110016

C. Jensen - Holm

Danish Engineering Academy

Dept. of Chemistry and Chemical Engineering

Bygning 375

2800 Lyngby, DENMARK

Mr. Don Huffman

Forintek Canada Corporation

800 Montreal Road

Ottawa, Ontario

KIG 325 CANADA

Mr. Richard J. Kania

INTEG

1155 West Pender Street

Vancouver, B.C.

U6E 2P4 CANADA 
Lyse Morisset

National Research Council of Canada

Suite $381, M-55$, Montreal Road

Ottawa, Ontario

KIA OR6 CANADA

\section{Ra1ph Overend}

Energy Project

National Research Council

of Canada

Ottawa, Ontario

KIA OR6 CANADA

Hans-Rolf Schulten

Fachhochschule Fresenius

Department of Trace Analysis

Dambachta 120

6200 WIESBADEN

Federal Republic of Germany

Sven Sjoeberg

Department of Chemical Technology

Royal instit. of Technology

Stockholm, S-10044, SWEDEN

Barbara Surmers

National Research Council of Canada

Bioenergy Program Manager

0ttawa, CANADA K1A OR6
Pacific Northwest Laboratory

P.0. Box 999

Richland, WA 99352

E. G. Baker

D. C. Elliott

M. A. Gerber

R. P. Marshall

G. A. McAtee

L. K. Mudge

G. F. Schiefelbein (20)

D. J. Stevens (12)

P. C. Walkup

Publishing Coordination (2)

Technical Information Library (5)

\section{ONSITE}

2 DOE Richland Operations

Harold E. Ransom, Oirector

Donald R. Segna 